FEDERAL

RESERVE

BANK of

RESEARCH DIVISION

Working Paper Series

ST. LOUIS

\title{
Financial Development and Long-Run Volatility Trends
}

\author{
Pengfei Wang \\ and \\ Yi Wen
}

Working Paper 2013-003C

https://doi.org/10.20955/wp.2013.003

August 2017

\author{
FEDERAL RESERVE BANK OF ST. LOUIS \\ Research Division \\ P.O. Box 442 \\ St. Louis, MO 63166
}

The views expressed are those of the individual authors and do not necessarily reflect official positions of the Federal Reserve Bank of St. Louis, the Federal Reserve System, or the Board of Governors.

Federal Reserve Bank of St. Louis Working Papers are preliminary materials circulated to stimulate discussion and critical comment. References in publications to Federal Reserve Bank of St. Louis Working Papers (other than an acknowledgment that the writer has had access to unpublished material) should be cleared with the author or authors. 


\title{
Financial Development and Long-Run Volatility Trends*
}

\author{
Pengfei Wang $^{a} \quad$ Yi Wen ${ }^{b} \quad$ Zhiwei Xuc
}

(This Version: August 18, 2017)

\begin{abstract}
Countries with more developed financial markets tend to have significantly lower aggregate volatility. This relationship is also highly non-linear - starting from a low level of financial development the reduction in aggregate volatility is far more significant with respect to financial deepening than when the financial market is more developed. We build a fully-fledged heterogeneous-agent model with an endogenous financial market of private credit and debt to rationalize these stylized facts. We show how financial development that promotes better credit allocations under more relaxed borrowing constraints can reduce the impact of non-financial shocks (such as TFP shocks, government spending shocks, preference shocks) on aggregate output and investment, and why this volatility-reducing effect diminishes with continuing financial liberalizations. Our simple model also sheds light on a number of other important issues, such as the "Great Moderation" and the simultaneously rising trends of dispersions in sales growth and stock returns for publicly traded firms.
\end{abstract}

Keywords: Financial Development, Firm Dynamics, Private Debts, Volatility Trends, Great Moderation, Lumpy Investment.

JEL codes: D21, D58, E22, E32.

${ }^{*} a$ : Department of Economics, Hong Kong University of Science \& Technology (e-mail: pfwang@ust.hk). $b$ : Research Department, Federal Reserve Bank of St. Louis (e-mail: yi.wen@stls.frb.org); SEM and PBCSF, Tsinghua University (e-mail: wenyi@sem.tsinghua.edu.cn). c: Antai College of Economics and Management, Shanghai Jiao Tong University (e-mail: xuzhiwei@sjtu.edu.cn). This paper was circulated originally with the title "Financial Development and Economic Volatility: A Unified Explanation." The views expressed are those of the individual authors and do not necessarily reflect official positions of the Federal Reserve Bank of St. Louis, the Federal Reserve System, or the Board of Governors. We thank Steven Davis, Vincenzo Quadrini, two anonymous referees and seminar participants at numerous institutions for comments, Mingyu Chen and Lifang $\mathrm{Xu}$ for outstanding research assistance, and Judy Ahlers for editorial assistance. Pengfei Wang acknowledges the financial support of the Hong Kong Research Grants Council (project \#643908). Zhiwei Xu acknowledges the financial support of the National Natural Science Foundation of China (No.71403166).The usual disclaimer applies. 


\section{Introduction}

Aggregate volatility is a central concern of government policies in both developed and developing countries. For example, optimal fiscal, monetary, and exchange rate policies are often discussed (or designed) in the context of how to best insulate the economy from exogenous shocks, or how to respond to such shocks to smooth aggregate fluctuations without themselves aggravating the business cycle. Yet, it has not been well recognized (or emphasized) by economists and policy makers that one of the most important forces to insulate the economy from external shocks (or to reduce economic volatility in the long term) may be financial development (FD). ${ }^{1}$

In light of the Asian financial crisis in 1998 and the recent financial crisis in 2008, perhaps it is easier to make a case for the opposite argument that FD often raises, instead of reduces, economic volatility. ${ }^{2}$ However, this short-run view does not square with data. Empirical studies based on cross-country evidences show that FD, as measured either by the size of the credit market relative to GDP or by the private debt-to-GDP ratio or other conventional statistics, is highly negatively correlated with aggregate economic volatility. For example, Easterly, Islam, and Stiglitz (2000) found that FD is negatively associated with aggregate output volatility, even after controlling for major macro factors. Bekaert, Harvey, and Lundblad (2004) show that financial liberalization leads to lower volatility in consumption growth and output growth. In particular, countries that have more open capital accounts experience a greater reduction in the variance of consumption and output growth after equity market openings. Dellasa and Hess (2005) document that FD can significantly reduce stockmarket volatility. Specifically, a deeper banking system is associated with lower volatility of aggregate stock returns. In addition, Braun and Larrain (2005) and Raddatz (2006) use a large (more than 100) crosscountry industry data and find that financial development lowers output volatility, more so in financially vulnerable sectors. Mangelli and Popov (2015) find that financial development can reduce aggregate volatility in OECD countries too.

Despite these important studies and empirical findings, the literature on the contribution of FD to economic volatility is rather thin, both empirically and theoretically, especially compared with the large and still growing literature on the causal relationship between FD and long-

\footnotetext{
${ }^{1}$ Obviously, by financial development we do not mean simple-minded reckless financial liberalizations. We mean measured financial development backed by establishment of prudential financial institutions and banking regulations to minimize fraud. Since such institutions are mostly endogenous to financial development and are often country-specific, our focus in this paper is on the long-run implications of financial development based on cross-country analysis.

${ }^{2}$ Also see Bernanke, Gertler, and Gilchrist (1999) on the financial accelerator mechanism.
} 
run economic growth (see Levine, 2005, for a literature review). This lack of empirical and theoretical work on the impact of FD on stability is surprising given the well-known long-run negative relationship between volatility and growth (see, e.g., Ramey and Ramey, 1995).

The strong negative correlation between FD and aggregate volatility may suggest a causal relation between financial development and economic volatility, or a third common factor driving their negative comovement, or a purely coincidental relationship. To support either possibility requires substantial empirical and theoretical work. This paper considers the first possibility that healthy financial development may reduce aggregate volatility in the long run.

How would FD exactly reduce economic volatility? Does it reduce aggregate volatility through promoting long-run growth (as suggested by the empirical study of Ramey and Ramey, 1995), or can there exist other channels? We believe the answer to such questions can not only improve our understanding on the business cycle but also shed new light on the long standing question of why FD promotes long-run growth itself.

Economists have long argued that FD fosters economic growth (Schumpeter, 1912; Goldsmith, 1969; McKinnon, 1973; King and Levine, 1993; among others), but despite more than half century of intensive research, consensus has not been reached, either empirically or theoretically, regarding the precise mechanisms through which this occurs. However, as Levine (2005) amply puts it, "[despite] subject to ample qualifications and countervailing views, the preponderance of evidence suggests that....better developed financial systems ease external financing constraints facing firms, which illuminates one mechanism through which FD influences economic growth" (Levine, 2005, p866).

For example, it is certainly possible that by relaxing firms' borrowing constraints, FD enables credit to be better allocated across firms, thus promoting investment efficiency and productivity growth (see, e.g., the theoretical model of Greenwood, Sanchez, and Wang, 2007). But if this $\mathrm{FD} \rightarrow$ credit $\rightarrow$ growth mechanism is correct, does it also help explain the negative relationship between FD and economic volatility? This is the question we attempt to answer in this paper, both empirically and theoretically.

The contribution of this paper is thus two-fold. (i) Using macroeconomic time series data from more than 100 countries covering the period of 1989-2006, we document (reconfirm) a robust negative relationship between FD and the variance of aggregate output and investment. Furthermore, this negative relationship is highly non-linear-starting from a low level of FD the marginal reduction in aggregate volatility associated with FD is quite dramatic, but the magnitude of volatility reduction diminishes quickly as the financial market develops further. This L-shaped convex relationship holds not only for the entire sample we have, but also for the sub-samples consisting of only industrial OECD countries, only emerging and newly industrial- 
ized economies, or only less developed countries. (ii) We build a tractable heterogeneous-agent general-equilibrium model with lumpy investment and endogenous credit markets to rationalize these stylized facts. We show how FD that relaxes collateral constraints can improve creditallocation efficiency across firms and consequently better insulate the economy from aggregate non-financial shocks, and why this volatility-reducing effect diminishes with continuing FD.

Therefore, our work not only corroborates the existing empirical studies, but also provides a theoretical framework to rationalize the empirical findings. In particular, by explicitly modeling the link between FD and firms' investment demand through borrowing constraints and credit reallocations, our model not only explains the negative non-linear relationship between FD and volatility, but also sheds light on the long-cherished causal mechanism linking FD to long-run growth through better credit arrangements, as emphasized by Levine (2005), as well as on the negative long-run relationship between volatility and growth documented by Ramey and Ramey $(1995) .^{3}$

The key mechanism in our model is the heterogeneity of firms' lumpy investment and the link between credit supply and firms' investment demand. Two well-known empirical facts about investment behavior are that, for both developed and developing countries, (i) aggregate investment fluctuations is the most volatile component in GDP, and (ii) firm-level investment is very lumpy (see, e.g., Caballero, 1999). Cooper and Haltiwanger (2006) document that at any moment only about $20 \%$ of firms undertake large investment (more than $20 \%$ of firms' assets) while most firms remain inactive. Lumpy investment implies that firms' saving behavior and investment demand do not necessarily coincide. In particular, it implies that a firm's investment demand is driven mainly by idiosyncratic shocks rather than aggregate shocks. This idiosyncratic nature of firm-level investment implies the potential gains from a credit (bond) market that facilitates cross-firm lending. We therefore explore the link between the depth of this particular credit market and firms' lumpy investment demand as well as their implications for aggregate capital accumulation, following Levine's (2005) suggestion, and aggregate volatility. ${ }^{4}$

Since firm investment requires both internal and external financing, better access to the credit market implies that aggregate non-financial shocks - such as aggregate productivity shocks, aggregate consumption demand shocks, and government spending shocks that directly and primarily affect firms' profits and cash flows - will have less impact on individual firms' investment decisions once firms become less dependent on internal cash flows for their investment decisions. In other words, FD and the deepening of credit markets enable more and more firms to make optimal investment decisions based on their own idiosyncratic needs rather than on

\footnotetext{
${ }^{3}$ Our current work does not explicitly model the corresponding changes in financial institutions and banking regulations accompanying financial development. This important issue is left for future research.

${ }^{4}$ We also explore our model's implications for firm-level volatility. See discussions below.
} 
aggregate shocks, thus dampening the uniform impact of such aggregate shocks on the average (aggregate) level of firm investments.

However, there are two margins through which aggregate investment can respond to aggregate shocks. On the intensive margin, the volatility of aggregate investment decreases with FD once firms become less dependent on internal cash flows but more dependent on external credit. On the extensive margin, since FD raises firms' borrowing limits and thus their sensitivity to favorable cash-flow shocks, in a deeper credit market a larger fraction of the firm population may opt to undertake investment under a positive shock to the cash flow. This extensive margin may thus serve as a counter-force to the intensive margin, so the stabilizing effect of FD on aggregate volatility is dampened, and the dampening effect grows stronger as borrowing constraints are further relaxed. In addition, if FD serves to encourage only the most productive (yet borrowing constrained) firms to increase their investment demand, then in general equilibrium there would be less firms investing and more firms lending through the credit market, thus reducing the number of investing firms and attenuating the impact of aggregate shocks on the business cycle through this extensive margin. ${ }^{5}$ This extensive-margin effect reinforces the L-shaped relationship between aggregate volatility and FD. ${ }^{6}$

Our explanation of the diminishing impact of FD on aggregate volatility based on the intensive and extensive margins immediately raises a new question: If firms become more leveraged under FD and their investment becomes less constrained by internal cash flows, would a deeper credit market render firm-level investment more volatile and lumpier, since firms with good investment opportunities can now invest more than they otherwise could? Would this in turn make aggregate investment more instead of less volatile?

We show that (i) FD indeed makes firm-level investment lumpier and more volatile; and (ii) however, despite a rising firm-level volatility, at the aggregate level the economy will become less volatile and more insulated from non-financial aggregate shocks. That is to say, a rising firm-level volatility and a falling aggregate volatility can go hand in hand. This means that countries with more developed financial systems can exhibit both a lower aggregate volatility and a higher firm-level volatility at the same time.

Surprisingly, available empirical evidence on the evolution of firm-level volatility does seem to support our predictions. A growing empirical literature shows that for publicly traded firms

\footnotetext{
${ }^{5}$ For example, the theoretical model of Greenwood, Sanchez, and Wang (2007) also predicts that the number of active investing firms decreases with FD because in the first-best case only the most productive firms need to invest while the less productive firms should lend. Hence, near the first-best point further FD should have little impact on aggregate investment.

${ }^{6}$ Our model also predicts that FD can increase aggregate volatility under financial shocks. This prediction is consistent with the recent 2008 financial crisis, during which financially more developed countries experienced higher aggregate volatility than financially less developed countries. Hence, our model provides a plausible reconciliation between the Great Moderation and the recent financial crisis. We address the issue of financial crisis at various places in the paper.
} 
in the United States (i.e., firms that are able to borrow from the financial markets), firmlevel volatility has been increasing over the postwar period, especially in the Great Moderation period. In particular, using financial data, Campbell et al. (2001) and Comin (2000) document increased volatility in firm-level stock returns. Using accounting data, Chaney, Gabaix, and Philippon (2002), Comin and Mulani (2006, 2009), and Comin and Philippon (2005) show increases in the idiosyncratic variability of capital investment, employment, sales, and earnings across firms. ${ }^{7}$ This rising trend in firm-level volatility coincided with financial liberalization and the Great Moderation in the U.S., and such a parallel development also occurred in other industrial countries. For example, Parker (2006) finds supporting evidence for an increasing trend in firm-level volatility in the United Kingdom over the period 1974-2004. This increase in volatility is found to accompany a widening of the distribution of firms' sales growth volatility and financial liberalization that relaxes firms' borrowing constraints. These results hold even when firm-specific factors, including size and age, are controlled for.

There are few theoretical studies on the relationship between FD and economic volatility. ${ }^{8}$ The work most closely related to ours is that of Aghion, Angeletos, Banerjee, and Manova (2007), which develops a three-period overlapping generations growth model in which firms engage in two types of investment: a short-term one and a long-term productivity-enhancing one. Because it takes longer time to complete, long-term investment has a relatively less procyclical return but also a higher liquidity risk. Under complete financial markets, these researchers show that long-term investment is countercyclical, thus mitigating volatility. But when firms face tight credit constraints, long-term investment turns procyclical, thus amplifying volatility. Tighter credit therefore leads to both higher aggregate volatility and lower mean growth for a given total investment rate. Their model thus predicts that FD reduces economic volatility and promotes long-run growth. ${ }^{9}$ They also use cross-country data to show that a lower degree of FD predicts a higher sensitivity of both the composition of investment and mean growth to exogenous shocks, as well as a stronger negative effect of volatility on growth.

In contrast to the work of Aghion, Angeletos, Banerjee, and Manova (2007), agents in our model are infinitely lived and our model can generate additional predictions of firm-level volatilities that are consistent with the data. The increase in firm-level volatility over time seems to contradict the negative effect of FD on aggregate volatility. However, we show that these diverging trends in firm-level and aggregate volatilities are the two sides of the same coin.

\footnotetext{
${ }^{7}$ Also see Davis, Haltiwanger, Jarmin, and Miranda (2006), Franco and Philippon (2004), and Guvenen and Philippon (2005), among others.

${ }^{8}$ See, for example, Campbell and Hercowitz (2006), Dynan, Elmendorf, and Sichel (2006a,b), Jermann and Quadrini (2009), Aghion, Angeletos, Banerjee, and Manova (2010), among others.

${ }^{9}$ Wang and Wen (2011) use a different endogenous growth model to show how growth rate and economic volatility can be negatively related.
} 
Another closely related work is that of Greenwood, Sanchez, and Wang (2007). They argue that FD (due to improvements in information technology) allows resources to be allocated to the most productive firms because of the reduction in verification costs for financial intermediaries. This cost-saving technology thus enhances the efficiency of resource allocation and long-run growth and explains the stylized fact that countries with better FD possess higher capital-to-output ratios. We develop an alternative framework of FD that also predicts more efficient resource allocation and higher capital-to-output ratios with financial liberalization. In our model the improvement in efficiency is achieved through self-selection of firms in an endogenously expanding financial market rather than through exogenously lowered monitoring costs in the banking sector as in their model. That is, FD relaxes borrowing constraints, which encourages more productive firms to undertake more fixed investment by raising funds through financial markets. Hence, firms with higher-return projects are more willing to borrow to invest in fixed capital, which increases the equilibrium spread in the marginal product of capital and the returns to financial assets (such as bonds). Meanwhile, firms with low-return projects (or poor investment opportunities) opt to invest their internal cash flows in financial assets rather than in fixed capital, which improves the supply of loanable funds. This self-selection mechanism enhances the efficiency of resource allocation across firms and raises the aggregate investment efficiency and the capital-to-output ratio. In addition, because of the improved aggregate efficiency in investment returns, the shadow marginal cost of investment is effectively lowered by FD (without requiring any investment-specific technology change). Hence, the competitive price of investment goods declines over time, consistent with empirical data (Greenwood, Hercowitz, and Krusell, 1997).

Unlike these aforementioned works, however, we do not directly model growth in this paper. Nonetheless, it is quite intuitive that improved credit allocation and investment efficiency under FD in our model should enhance long-run growth once endogenous growth through more effective accumulation of both fixed and human capital is allowed (such as in a AK model). Therefore, we expect that an enriched version of our model with endogenous growth will predict a positive relationship between FD and long-run growth. This task is left for our future studies. ${ }^{10}$

The rest of the paper is organized as follows. Section 2 presents the empirical fact on the non-linear negative relationship between FD and aggregate volatility in the data. Sections 3 and 4 present our theoretical model and characterize the general-equilibrium properties of the model. Section 5 uses our model to explain the negative non-linear relationship between FD and aggregate volatility. Section 6 studies the model's implications for the rising trend

\footnotetext{
${ }^{10}$ The is also a large literature on the business cycles in emerging countries (e.g. Aguiar and Gopinath 2007; Neumeyer and Perri, 2005; among others). See Section 7.4 for literature review and discussions.
} 
in firm-level volatility and dispersion found in the U.S. data. Section 7 provides a series of robustness analyses to test quantitatively the explanatory power of our model. The most important robustness analysis performed therein is a country-by-country estimation of financial development and other key structural parameters in our model against available data, which takes full control of the aggregate shocks in each country. The estimation results confirm the L-shaped relationship. This particular robustness analysis addresses the concern that the reduction of aggregate volatility in financially more developed countries may be the result of smaller aggregate shocks rather than better financial development. Finally, section 8 concludes the paper.

\section{Empirical Facts}

Using panel data from 106 countries (1989-2006), this section documents a systematic non-linear negative relationship between FD and aggregate economic volatility. ${ }^{11}$ We measure aggregate volatility by the variance of GDP (or investment) growth. Following King and Levine (1993), the degree of FD is measured by the total private credit-to-GDP ratio. As a robustness check, three different measures for private credit supply are used to compute the index of FD, including total domestic credit from the banking industry (source: World Bank), total claims on private sectors (source: IMF), and total private credit from the financial industry (source: Beck, Kunt, and Levine, 2010). These three different measures may differ greatly for each country. For example, the constructed FD index (credit supply-to-GDP ratio $\times 100$ ) for the U.S. is $190,50,151$, respectively, by the three measures. We label these different measures as FD1, FD2, and FD3. We show that the L-shaped relationship between aggregate volatility and FD exists regardless of which measure of FD is used, and that it holds also for aggregate investment volatility, consistent with our belief that financial development reduces aggregate output volatility through its impact on firms' investment. ${ }^{12}$

In what follows, we divide our entire sample into three subsamples, labeled OECD for developed countries, emerging and newly industrialized (ENI) economies, and the less developed countries (LDC). For each subsample, we estimate the non-linear trend (a deterministic power

\footnotetext{
${ }^{11}$ As our model shows, financial development can magnify volatility under financial shocks, but reduce volatility under non-financial shocks; hence, we used data until 2006 to avoid the financial shock driven period. However, in a latter section (Section 7) we use quarterly data updated to 2014Q4 and show that a negative relationship between FD and aggregate volatility is robust.

${ }^{12}$ In addition, we also use two additional measures to check the robustness of our empirical findings. First, we use the "financial liberalization index" constructed by Kaminsky and Schmukler (2008) to measure FD, which captures changes in financial regimes and indicates the level of financial liberalization in a nation. Second, we use credit to non-financial corporations as \% of GDP from BIS dataset as an indicator for financial development. In both cases we find similar negative relationship between FD and aggregate volatility. See Appendix VI (or Online Appendix B) for details.
} 
series) between FD and volatility for each measure of FD.

\section{OECD Countries.}

Figure 1 (panels A, B, and C) shows that there is a non-linear negative relationship between aggregate output volatility and FD for OECD countries, where the vertical axis represents aggregate volatility, the horizontal axis represents FD (measured by total private credit-to-GDP ratio $\times 100$ ), and the smooth dashed line in each window represents the result of a non-linear regression between the two data series. Specifically, panels A, B, and C show the variance of GDP growth against the first, second, and third measure of FD. Panel D shows the variance of aggregate investment growth against FD3. ${ }^{13}$
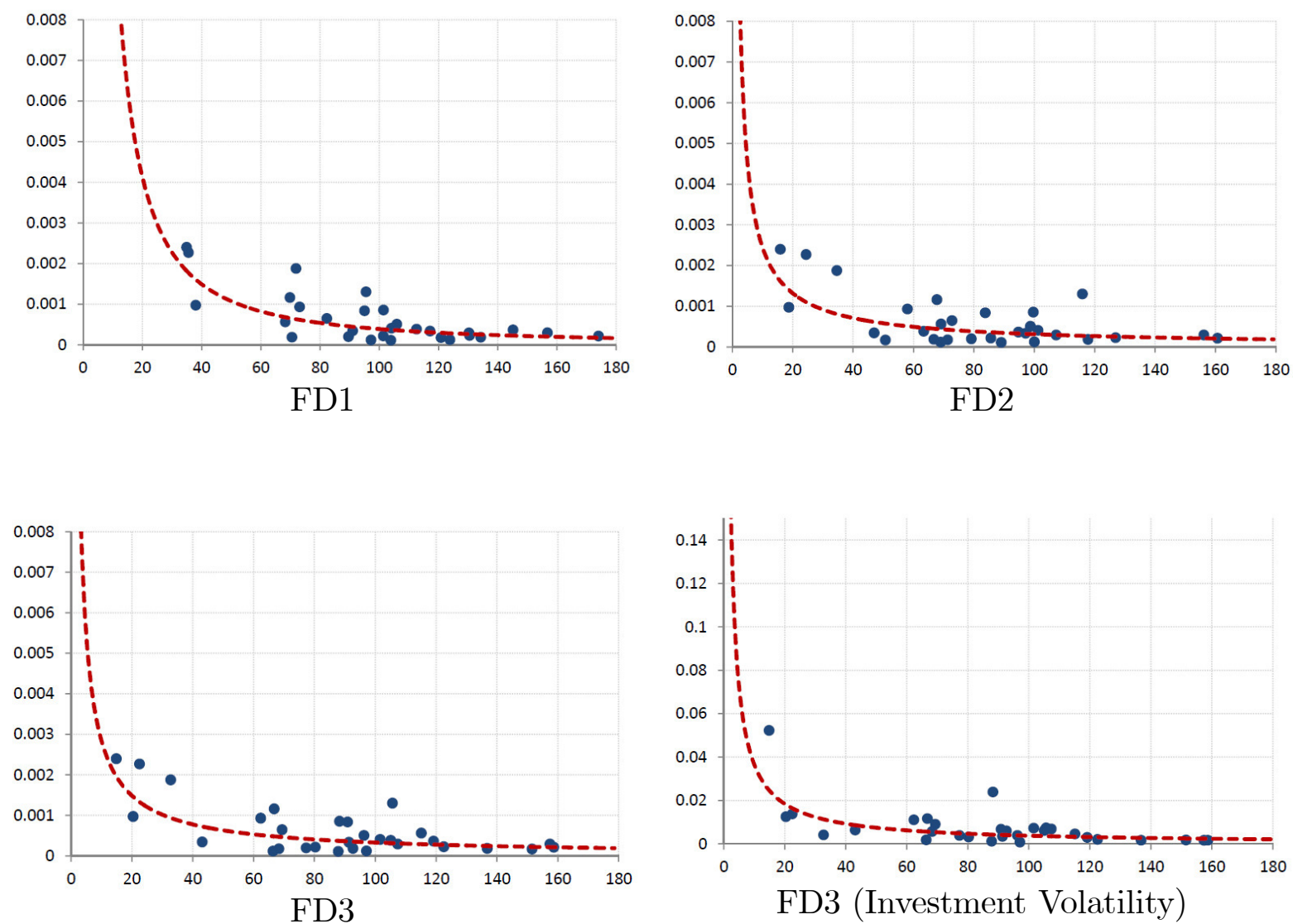

Figure 1. Relation between volatility (y-axis) and FD (x-axis) for OECD.

\footnotetext{
${ }^{13}$ The results are similar for FD1 and FD2.
} 
Because OECD countries in general are less volatile and more financially developed than the other countries in our sample, the data points are clustered towards the lower end of Lshaped non-linear line. We have extended the non-linear trend line backwards by out-of-sample extrapolation, so the upper end of the non-linear line can be viewed as out-of-sample predictions for financially less developed countries. Panel D shows that the same non-linear relationship and clustering holds between the variance of aggregate investment growth and FD. In addition, corresponding to each level of FD, investment growth is a couple of orders more volatile than GDP growth (see the magnitudes of the vertical axis).

\section{Emerging and Newly Industrialized Economies.}
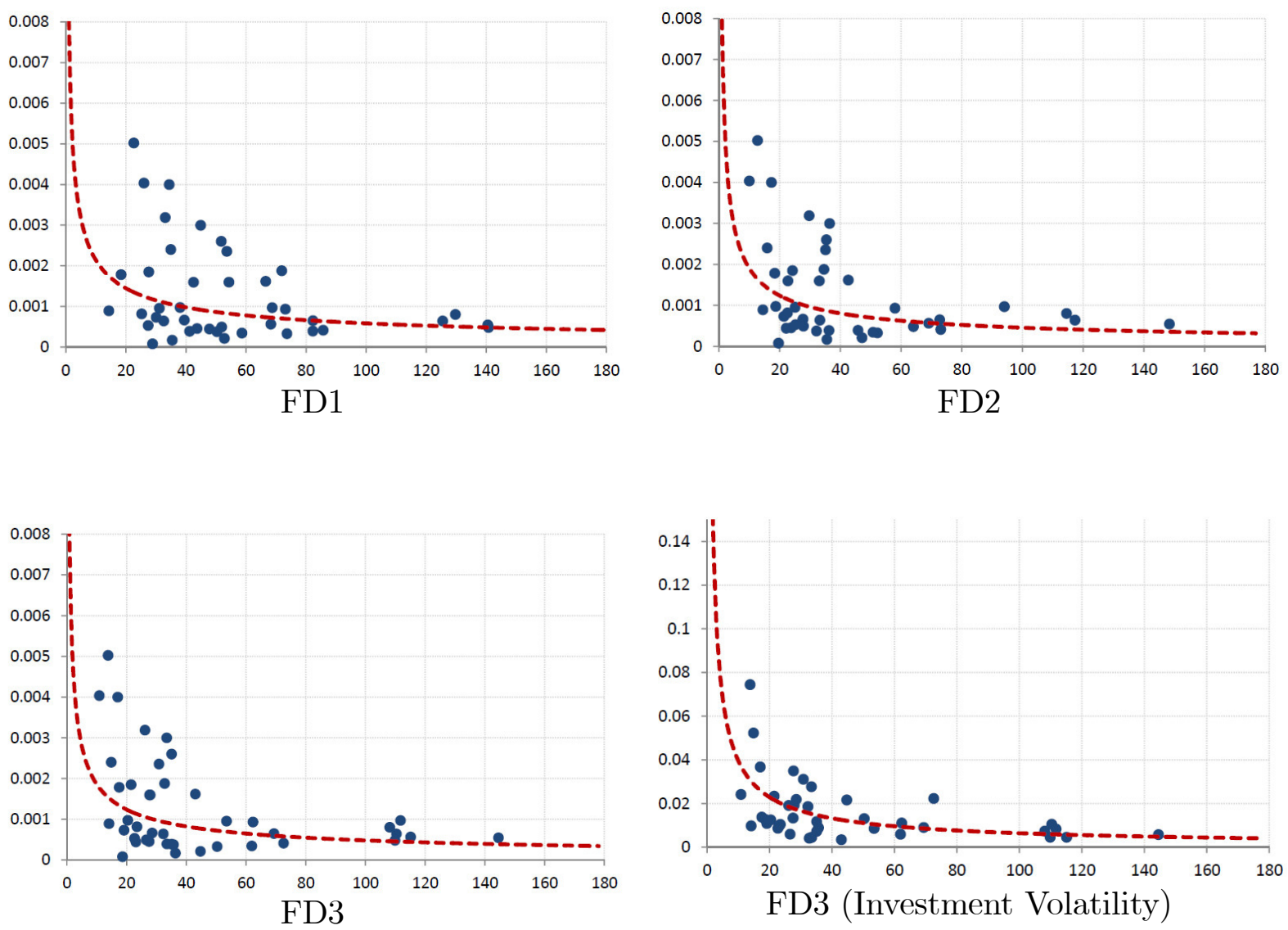

Figure 2. Relation between volatility (y-axis) and FD (x-axis) for ENI.

Next, we show that the same L-shaped relationship holds for the ENI countries (Figure 2). There are 44 economies in this category, including the emerging Asian economies, such as 
Singapore, Hong Kong, South Korea, and Thailand. We exclude the Asian financial crisis year (1998) when computing the Asian economies' average growth rate of GDP (or investment) and the FD measures. ${ }^{14}$

Clearly, the four panels in Figure 2 all point to an L-shaped relationship between aggregate volatility and our FD measures. Compared with OECD countries, ENI economies tend to have lower levels of FD but higher levels of aggregate volatility; namely, the data points in each of the four panels in Figure 2 are distributed and clustered more around the bend of the L-shaped non-linear line. Again, panel D shows that the same non-linear relationship and clustering hold for the variance of aggregate investment growth and that investment growth is a couple of orders of magnitude more volatile than GDP growth at each level of FD.

\section{Less Developed Countries.}
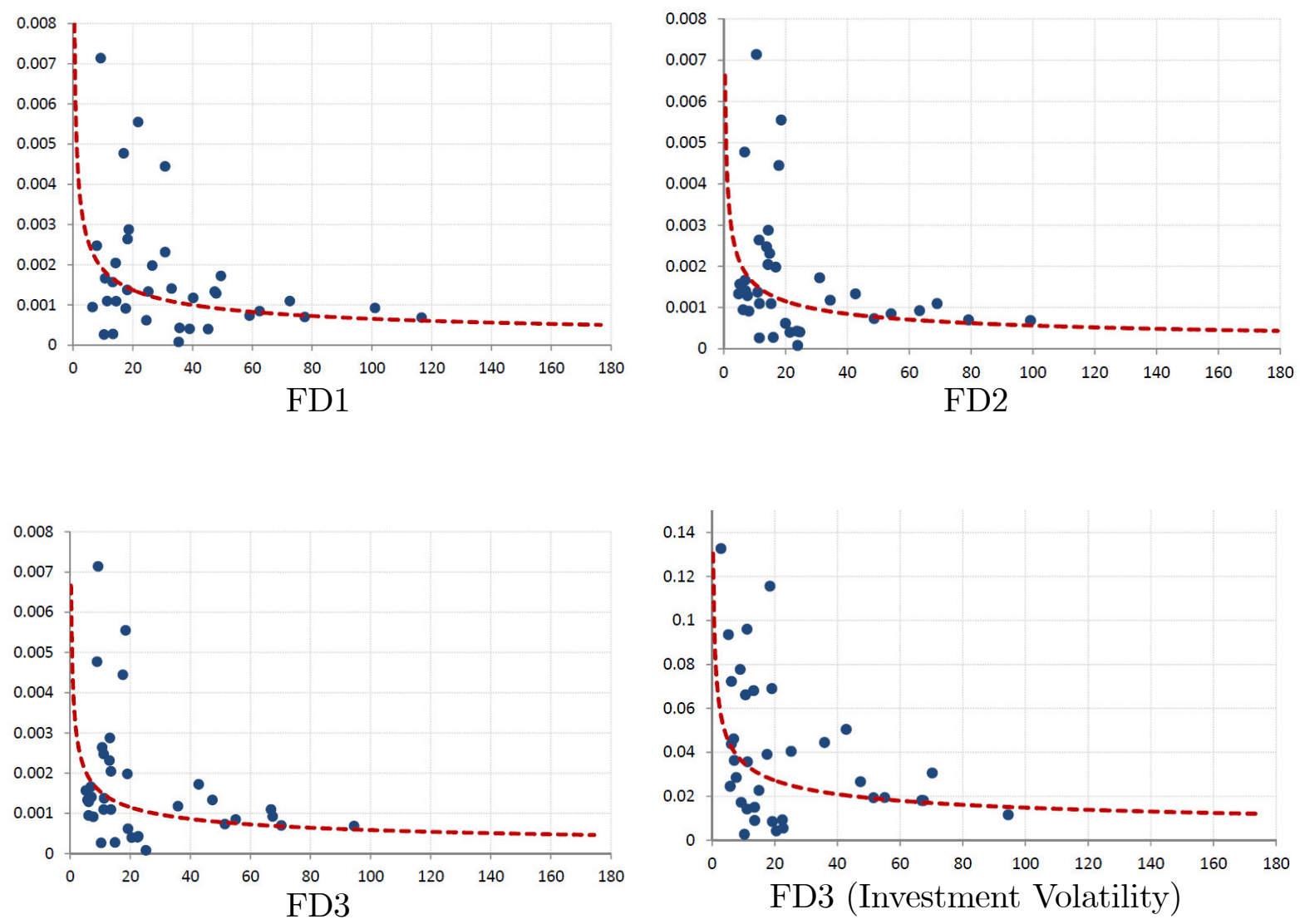

Figure 3. Relation between volatility (y-axis) and FD (x-axis) in for LDCs.

\footnotetext{
${ }^{14}$ The effects of financial crisis on the L-shaped relationship are presented in Figure 5.
} 
The rest of the countries in our sample (excluding OECD countries in Figure 1 and the emerging economies in Figure 2) are graphed in Figure 3. Clearly, the LDCs also show the same L-shaped relationship between aggregate volatility and FD. The data points in each panel in Figure 3 are clustered around the bend but more towards the upper end of the L-shaped nonlinear line, suggesting that these countries tend to have significantly less FD and significantly higher aggregate volatility than the first two groups of countries in our total sample.

\section{All Countries.}
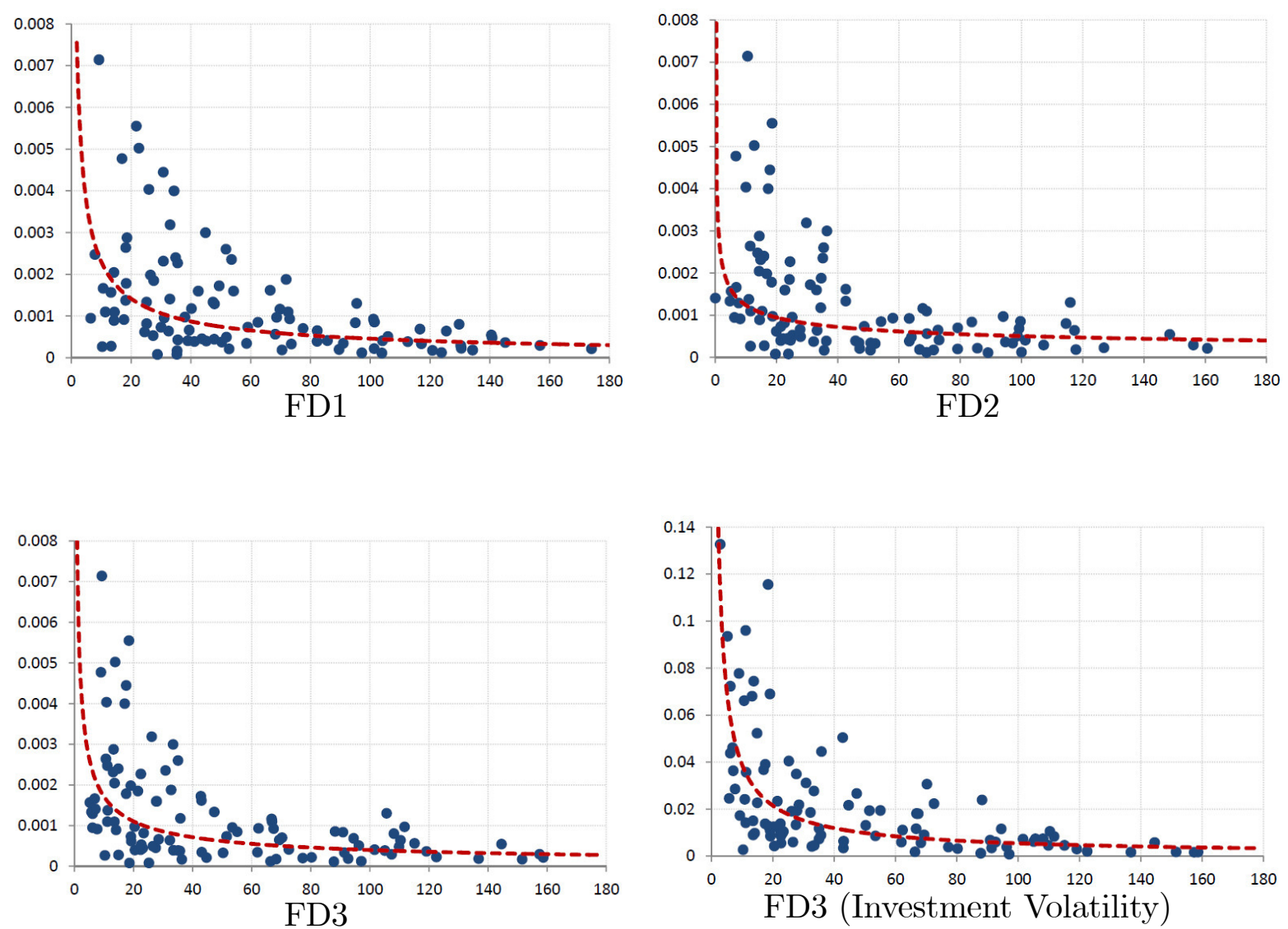

Figure 4. Relation between volatility (y-axis) and FD (x-axis) for all countries.

Each panel in Figure 4 pulls all of the countries together with a reestimated non-linear trend. They show that an L-shaped relationship holds true for the entire sample of countries with respect to each measure of FD. It is also clear in panel D that this L-shaped relationship between aggregate volatility and FD is just as sharp (or even more so) for investment as it is for GDP, even though investment growth is a couple of orders of magnitude more volatile 
than GDP growth and that this dramatically higher volatility is more likely to distort any clear relationship. This clear and sharp L-shaped relationship between FD and investment volatility is consistent with our theory that FD may reduce aggregate output volatility primarily through its effects on aggregate investment volatility.

\section{Financial Crisis.}

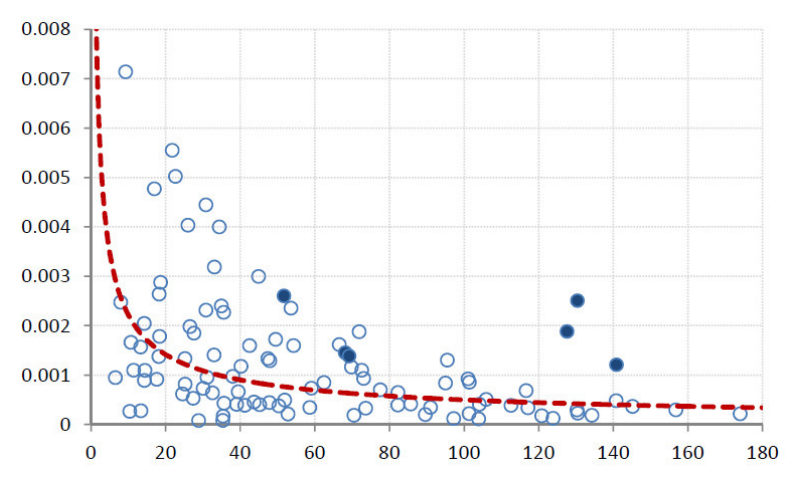

FD1

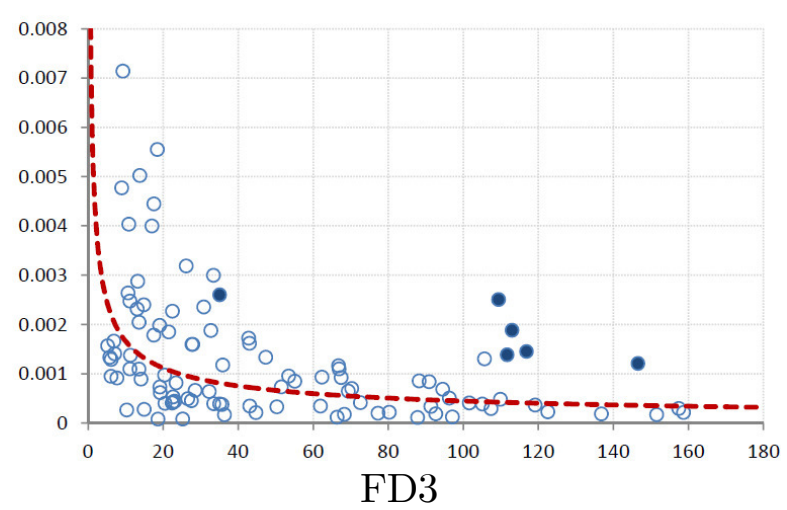

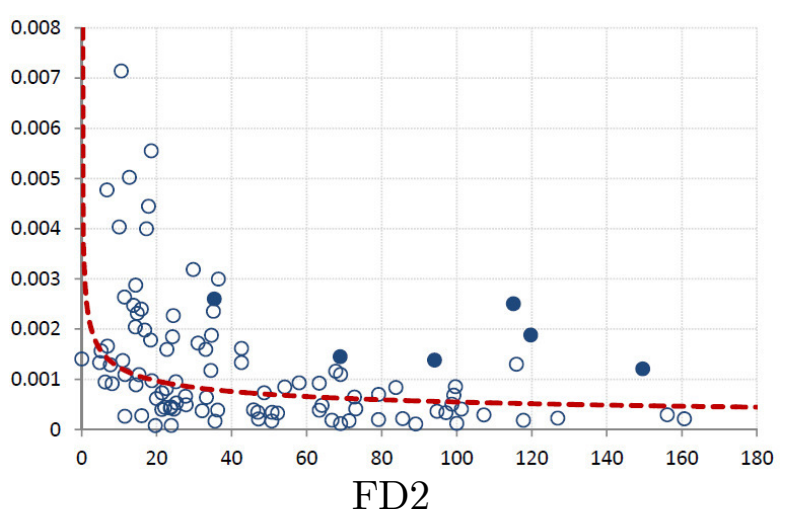

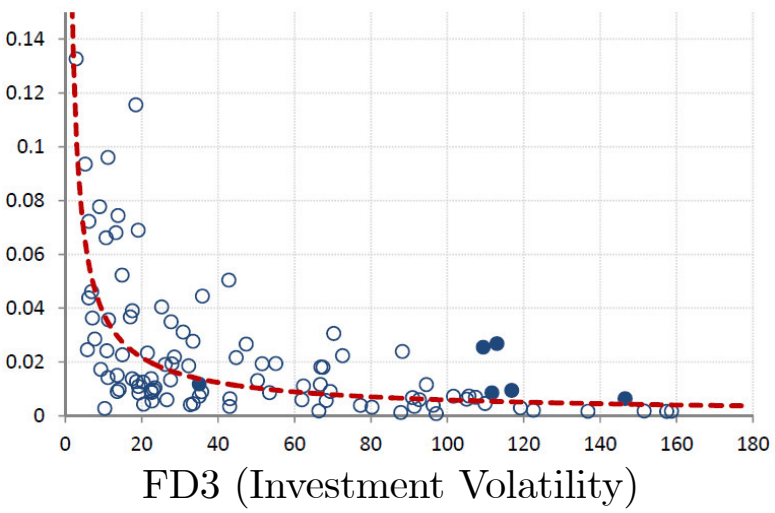

Figure 5. Impact of Asian Financial Crisis (solid circles).

Finally, we ask whether FD may render a country more susceptible to financial shocks. Our sample covers an important financial crisis period - the Asian financial crisis in 1998. There are six economies in our sample that were significantly affected by the crisis, including Hong Kong, Indonesia, Korea, Malaysia, Singapore, and Thailand. Each of these economies experienced sharp declines in GDP growth in 1998, which may have increased their overall variance of GDP growth. In the previous volatility estimations, the growth rates of GDP (or investment) in 1998 were deleted for these economies. Figure 5 shows the reestimated non-linear trend lines with 
the Asian financial crisis period included. To highlight the effect of the financial crisis, the economies affected by the crisis are represented by solid circles and the rest by empty circles. All panels in Figure 5 show that the Asian financial crisis significantly increased the overall aggregate volatility for the six affected economies.

Although the L-shaped trend line in each panel of Figure 5 is not significantly affected by the inclusion of the financial crisis period, each panel in the figure does suggest that FD can increase (instead of decrease) a country's aggregate volatility under financial (instead of non-financial) shocks. This additional piece of information serves as an independent robustness check of our theoretical model and we will show that our model is also consistent with the fact that FD's influences on financial shocks and non-financial shocks are quite distinct.

\section{Robustness.}

Figures 1-5 illustrate the L-shaped negative correlation between macroeconomic volatility and the index of financial development. However, such correlations may be driven by some common omitted factors. For example, both volatility and financial development may be influenced by real economic development in other dimensions, such as exchange rate regimes, changes in per-capita GDP, openness to trade, terms of trade, international capital flows, inflation, real interest rate and money supply, etc. Using multivariate non-linear regression, we find that the L-shaped correlation between macro volatility and financial development is robust to the inclusion of additional controls. To converse space, the results are reported in Appendix IV. ${ }^{15}$

\section{The Model}

Time is discrete and indexed by $t=0,1,2, \ldots$. There is a continuum of heterogeneous firms indexed by $i$ and distributed over the closed interval $[0,1]$. There is also a continuum of identical households, who trade all firms' shares. There are four types of aggregate non-financial shocks in the economy, including shocks to households' marginal utility of consumption $\left(\Omega_{c t}\right)$, shocks to households' marginal utility of leisure $\left(\Omega_{n t}\right)$, shocks to government spending $\left(G_{t}\right)$, and shocks to firms' production technology $\left(A_{t}\right)$. Each firm is also subject to an idiosyncratic investmentefficiency shock $\left(\varepsilon_{t}(i)\right)$. Investment is irreversible, so firms have incentives to wait (to be inactive) when there is a lack of good investment opportunities. Firms can borrow from a financial market by issuing debts. However, due to limited contract enforceability, a firm's debt level is limited by its collateral.

\footnotetext{
${ }^{15}$ Also see Section 7 for more discussions on robustness analyses.
} 


\subsection{Firm $i$ 's Problem}

Firm $i$ 's objective is to maximize the present value of its discounted future dividends,

$$
V_{t}(i)=\max E_{t} \sum_{\tau=0}^{\infty} \beta^{\tau} \frac{\Lambda_{t+\tau}}{\Lambda_{t}} d_{t+\tau}(i),
$$

where $d_{t}(i)$ is firm $i$ 's dividend in period $t$ and $\Lambda_{t}$ is the representative household's marginal utility, which firms take as given. The production technology of firm $i$ is given by a constant returns to scale function,

$$
y_{t}(i)=G\left(k_{t}(i), A_{t} n_{t}(i)\right)
$$

where $A_{t}$ represents aggregate labor-augmenting technology, and $n(i)$ and $k(i)$ are firm-level employment and capital, respectively. Each firm accumulates capital according to the law of motion,

$$
k_{t+1}(i)=(1-\delta) k_{t}(i)+\varepsilon_{t}(i) i_{t}(i)
$$

where

$$
i_{t}(i) \geq 0
$$

denotes irreversible investment and $\varepsilon(i)$ is an idiosyncratic shock to the marginal efficiency of investment, which has the cumulative distribution function $F(\varepsilon)$. In each period $t$, a firm needs to pay wages $w_{t} n_{t}(i)$, decide whether to invest in fixed capital and distribute dividends $d(i)$ to households.

Firms' investment is financed by internal cash flow and external funds. Firms raise external funds by issuing one-period debt (bonds), $b_{t+1}(i)$, which pays the competitive market interest rate $r_{t} \geq 1$. We focus on debt financing because it accounts for $75 \%$ to $100 \%$ of the total external funds of corporations. ${ }^{16}$ A firm can invest in bonds issued by other firms (i.e., $b_{t+1}(i)$ can be negative). ${ }^{17}$

A firm's dividend in period $t$ is then given by

$$
d_{t}(i)=y_{t}(i)+\frac{b_{t+1}(i)}{r_{t}}-i_{t}(i)-w_{t} n_{t}(i)-b_{t}(i)
$$

Firms cannot pay negative dividends:

\footnotetext{
${ }^{16}$ Source: Flow of Funds Accounts of the United States.

${ }^{17}$ Firms do not have to lend to each other directly. Intrafirm lending can be arranged through financial intermediation.
} 


$$
d_{t}(i) \geq 0
$$

which is the same as saying that fixed investment is financed entirely by internal cash flow $\left(y_{t}(i)-w_{t} n_{t}(i)\right)$ and external funds net of loan repayment $\left(\frac{b_{t+1}(i)}{r_{t}}-b_{t}(i)\right)$.

Because of imperfect financial markets, firms are borrowing constrained. ${ }^{18}$ We impose the following borrowing limit as Kiyotaki and Moore (1997) do,

$$
b_{t+1}(i) \leq \theta k_{t}(i)
$$

which specifies that any new debt issued cannot exceed a proportion $\theta$ of the collateral value of a firms' existing capital stock. Parameter $\theta \geq 0$ measures the degree of FD - the larger the value of $\theta$, the more developed the financial market. When $\theta=0$, the model is identical to one that prohibits external financing. ${ }^{19}$

Notice that an important departure of our financial-friction framework from that of Kiyotaki and Moore (1997) is that our approach does not rely on the assumptions that lenders and borrowers have different time-discounting factors and that borrowing constraints are always binding. It is not empirically clear who those impatient borrowers and patient lenders are in the real world. In contrast, each firm in our model can be either a borrower (issuing bonds to the public) or a lender (buying bonds from other firms), depending on the firm's financial conditions. Another methodological contribution of this paper is that we derive analytically tractable firm-level decision rules in spite of borrowing constraints, irreversible investment, and firm heterogeneity. ${ }^{20}$ The method allows us to study the model's aggregate dynamics without relying on numerical computational methods (unlike what Krusell and Smith (1998) do). The accuracy of numerical methods in solving heterogeneous-agent models is very much model dependent and there is no guarantee that an equilibrium exists or is unique. Our ability to solve the decision rules analytically in our model not only allows us to prove the existence and uniqueness of equilibrium but also renders transparent the economic mechanisms linking financial frictions and economic volatility. ${ }^{21}$

\footnotetext{
${ }^{18}$ Fazzari, Hubbard, and Petersen (1988) provide empirical evidence on firms' borrowing constraints and emphasize imperfections in the equity and debt markets.

${ }^{19}$ If firms cannot issue bonds, then the bond market would not exist. Hence, $b_{t+1}(i)=0$ for all $i$ in equilibrium.

${ }^{20}$ For a related approach, see Caplin and Leahy (2006) where they construct a tractable model with lumpy durable consumption adjustment.

${ }^{21}$ Similar analytical methods have been used by Wang and Wen (2012) to solve heterogeneous-firm models with multiple equilibria. The method of Krusell and Smith (1998) do not work in such an environment (see, e.g., Peralta-Alva and Santos, 2010).
} 


\subsection{The Household's Problem}

A representative household chooses a level of consumption $C_{t}$, labor supply $N_{t}$, and share holdings of each firm $\left(s_{t+1}(i)\right)$ to solve

$$
\max \sum_{t=0}^{\infty} \beta^{t}\left\{\Omega_{c t} \log C_{t}-\Omega_{n t} \frac{N_{t}^{1+\gamma}}{1+\gamma}\right\}
$$

subject to the budget constraint,

$$
C_{t}+G_{t}+\int s_{t+1}(i)\left[V_{t}(i)-d_{t}(i)\right] d i \leq w_{t} N_{t}+\int s_{t}(i) V_{t}(i) d i
$$

where $\left\{\Omega_{c t}, \Omega_{n t}\right\}$ represent preference shocks to the marginal utility of consumption and leisure, respectively, $G_{t}$ denotes shocks to government expenditure (financed by lump-sum income taxes), $s_{t}(i)$ is firm $i$ 's stock shares and $V_{t}(i)$ is the value of the firm (or its stock price). ${ }^{22}$ Let $\Lambda_{t}$ be the Lagrangian multiplier of budget constraint (9). The first-order conditions for $\left\{C_{t}, N_{t}, s_{t+1}(i)\right\}$ are given, respectively, by

$$
\begin{gathered}
\Lambda_{t}=\frac{\Omega_{c t}}{C_{t}} \\
\Lambda_{t} w_{t}=\Omega_{n t} N_{t}^{\gamma}, \\
V_{t}(i)=d_{t}(i)+E_{t} \beta \frac{\Lambda_{t+1}}{\Lambda_{t}} V_{t+1}(i) .
\end{gathered}
$$

Equation (12) implies that the stock price $V_{t}(i)$ is determined by the present value of this firm's discounted future dividends, as in equation (1).

\subsection{Competitive Equilibrium}

A competitive equilibrium is the sequences of quantities $\left\{C_{t}, N_{t}\right\}_{t=0}^{\infty}$ and $\left\{i_{t}(i), n_{t}(i), y_{t}(i)\right.$, $\left.k_{t+1}(i), b_{t+1}(i)\right\}_{t \geq 0}$ for $i \in[0,1]$, and the sequence of prices $\left\{w_{t}, V_{t}(i), r_{t}\right\}_{t=0}^{\infty}$ such that

(i) Given prices $\left\{w_{t}, r_{t}\right\}_{t \geq 0}$ and any aggregate shocks, the sequence $\left\{i_{t}(i), n_{t}(i), y_{t}(i), k_{t+1}(i)\right.$, $\left.b_{t+1}(i)\right\}_{t \geq 0}$ solves firm $i$ 's problem (1) subject to constraints (2)-(7).

\footnotetext{
${ }^{22}$ We will show that the household has no incentive to buy bonds issued by firms in equilibrium.
} 
(ii) Given prices $\left\{w_{t}, V_{t}(i)\right\}_{t \geq 0}$ and any aggregate shocks, the sequence $\left\{C_{t}, N_{t}, s_{t+1}(i)\right\}_{t \geq 0}$ maximizes household utility subject to budget constraint (9).

(iii) All markets clear:

$$
\begin{gathered}
s_{t+1}(i)=1 \quad \text { for all } i \in[0,1] \\
N_{t}=\int n_{t}(i) d i \\
C_{t}+G_{t}+\int i_{t}(i)=\int y_{t}(i) d i
\end{gathered}
$$

\section{Equilibrium Properties}

\subsection{A Firm's Decision Rules}

Given the real wage, a firm's labor demand is determined by the first-order condition

$$
w_{t}=G_{n}^{\prime}\left(k_{t}(i), A_{t} n_{t}(i)\right)
$$

Constant returns to scale of the production function then implies that both the output-to-capital

ratio $\frac{y_{t}(i)}{k_{t}(i)}$ and the labor-to-capital ratio $\frac{n_{t}(i)}{k_{t}(i)}$ are independent of the index $i$ (i.e., identical across firms). Hence, we can define a firm's net revenue as a linear function of its capital stock,

$$
y_{t}(i)-w_{t} n_{t}(i) \equiv R\left(w_{t}, A_{t}\right) k_{t}(i)
$$

where $R_{t}$ is a function of the real wage and the technology level. This linear relationship between cash flow and the capital stock implies that the aggregate cash flow will depend only on the aggregate capital stock. This means that there is no need to track the distribution of $k_{t}(i)$ in formulating aggregate dynamics, thus simplifying the analysis. Notice that the function $R$ also captures the effects of other aggregate shocks (such as preference and government spending shocks) as they affect the equilibrium real wage through firms' labor demand.

Applying the definition in equation (17), the firm's problem can be rewritten as

$$
\max _{\left\{i_{t}(i), b_{t+1}(i), k_{t+1}(i)\right\}} E_{0} \sum_{t=0}^{\infty} \beta^{t} \frac{\Lambda_{t}}{\Lambda_{0}}\left(R_{t} k_{t}(i)+\frac{b_{t+1}(i)}{r_{t}}-b_{t}(i)-i_{t}(i)\right)
$$

subject to 


$$
\begin{gathered}
k_{t+1}(i)=(1-\delta) k_{t}(i)+\varepsilon_{t}(i) i_{t}(i) \\
i_{t}(i) \geq 0 \\
i_{t}(i) \leq R_{t} k_{t}(i)+\frac{b_{t+1}(i)}{r_{t}}-b_{t}(i) \\
b_{t+1}(i) \leq \theta k_{t}(i)
\end{gathered}
$$

Denoting $\left\{\lambda_{t}(i), \pi_{t}(i), \mu_{t}(i), \phi_{t}(i)\right\}$ as the Lagrangian multipliers of constraints (19)-(22), respectively, the firm's first-order conditions for $\left\{i_{t}(i), k_{t+1}(i), b_{t+1}(i)\right\}$ are given, respectively, by

$$
\begin{gathered}
1+\mu_{t}(i)=\varepsilon_{t}(i) \lambda_{t}(i)+\pi_{t}(i), \\
\lambda_{t}(i)=\beta E_{t} \frac{\Lambda_{t+1}}{\Lambda_{t}}\left\{\left[1+\mu_{t+1}(i)\right] R_{t+1}+(1-\delta) \lambda_{t+1}(i)+\theta \phi_{t+1}(i)\right\} \\
\frac{\left[1+\mu_{t}(i)\right]}{r_{t}}=\beta E_{t} \frac{\Lambda_{t+1}}{\Lambda_{t}}\left\{\left[1+\mu_{t+1}(i)\right]\right\}+\phi_{t}(i) .
\end{gathered}
$$

The complementarity slackness conditions are $\pi_{t}(i) i_{t}(i)=0,\left[R_{t} k_{t}(i)-i_{t}(i)+\frac{b_{t+1}(i)}{r_{t}}-b_{t}(i)\right] \mu_{t}(i)=$ 0 , and $\phi_{t}(i)\left[\theta k_{t}(i)-b_{t+1}(i)\right]=0$.

Proposition 1 The decision rule for investment is characterized by an optimal trigger strategy featuring an endogenous cutoff value $\varepsilon_{t}^{*}$ such that the firm invests if and only if $\varepsilon_{t}(i) \geq \varepsilon_{t}^{*}$ :

$$
i_{t}(i)=\left\{\begin{array}{cl}
{\left[R_{t}+\frac{\theta}{r_{t}}\right] k_{t}(i)-b_{t}(i) .} & \text { if } \varepsilon_{t}(i) \geq \varepsilon_{t}^{*} \\
0 & \text { if } \varepsilon_{t}(i)<\varepsilon_{t}^{*}
\end{array} .\right.
$$

The cutoff $\varepsilon_{t}^{*} \equiv \frac{1}{\lambda_{t}}$ is independent of $i$ and determined by the Euler equation

$$
\frac{1}{\varepsilon_{t}^{*}}=\beta E_{t} \frac{\Lambda_{t+1}}{\Lambda_{t}}\left\{R_{t+1} Q\left(\varepsilon_{t+1}^{*}\right)+\frac{(1-\delta)}{\varepsilon_{t+1}^{*}}+\frac{\theta}{r_{t+1}}\left(Q\left(\varepsilon_{t+1}^{*}\right)-1\right)\right\}
$$

where $Q\left(\varepsilon_{t}^{*}\right) \equiv 1+\int_{\varepsilon(i) \geq \varepsilon^{*}} \frac{\varepsilon_{t}(i)-\varepsilon_{t}^{*}}{\varepsilon_{t}^{*}} d F(\varepsilon)$.

Proof. See Appendix I. 
The intuition underlying the firm's investment decision rule is straightforward. The marginal cost of investment is 1 , and its marginal benefit is $\varepsilon_{t}(i) \lambda_{t}(i)$, where $\varepsilon_{t}(i)$ measures the efficiency of investment and $\lambda_{t}(i)$ the market value of one unit of newly installed capital. Thus, Tobin's $q$ for firm $i$ is given by $q_{t}(i) \equiv \varepsilon_{t}(i) \lambda_{t}(i)$. The firm will invest if and only if $q_{t}(i) \geq 1$, or $\varepsilon_{t}(i) \geq \lambda_{t}(i)^{-1}$. Hence, the optimal cutoff is given by $\varepsilon_{t}^{*}=\frac{1}{\lambda_{t}(i)}$. Since $\varepsilon_{t}(i)$ is i.i.d. and orthogonal to aggregate shocks, by the law of iterated expectations, equation (24) becomes

$$
\lambda_{t}(i)=\beta E_{t} \frac{\Lambda_{t+1}}{\Lambda_{t}}\left\{\left[1+\bar{\mu}_{t+1}\right] R_{t+1}+(1-\delta) \bar{\lambda}_{t+1}+\theta \bar{\phi}_{t+1}\right\},
$$

where $\bar{\mu}_{t+1} \equiv \int \mu_{t+1}(\varepsilon) d F(\varepsilon), \bar{\lambda}_{t+1} \equiv \int \lambda_{t+1}(\varepsilon) d F(\varepsilon)$, and $\bar{\phi}_{t+1} \equiv \int \phi_{t+1}(\varepsilon) d F(\varepsilon)$, with all being independent of $i$, so that $\lambda_{t}(i)$ (the left-hand side of the equation) is also independent of $i$. That is, the market value of one unit of newly installed capital is the same across firms because the expected future marginal products of newly installed capital are independent of the current shock $\varepsilon_{t}(i)$. This also explains why the cutoff is independent of $i$.

Notice that $Q\left(\varepsilon_{t}^{*}\right) \equiv E\left[1+\mu_{t}(i)\right]$ measures the option value of one unit of cash flow. Given one dollar in hand, if it is not invested (because $\left.\varepsilon_{t}(i)<\varepsilon_{t}^{*}\right)$, its value is still one dollar $\left(\mu_{t}(i)=0\right)$. This case occurs with probability $F\left(\varepsilon_{t}^{*}\right)$. If $\varepsilon_{t}(i) \geq \varepsilon_{t}^{*}$, one unit of cash flow can produce $\varepsilon_{t}(i)$ units of new capital and the cash return is $\varepsilon_{t}(i) \lambda_{t}=\frac{\varepsilon_{t}(i)}{\varepsilon_{t}^{*}}$ dollars. This case occurs with probability $1-F\left(\varepsilon_{t}^{*}\right)$. Therefore, the expected value of one dollar is $Q\left(\varepsilon_{t}^{*}\right)=F\left(\varepsilon_{t}^{*}\right)+$ $\int_{\varepsilon \geq \varepsilon^{*}} \frac{\varepsilon(i)}{\varepsilon_{t}^{*}} d F=1+\int_{\varepsilon(i) \geq \varepsilon^{*}} \frac{\varepsilon(i)-\varepsilon_{t}^{*}}{\varepsilon_{t}^{*}} d F(\varepsilon)>1$.

Equation (27) is an asset-pricing equation for determining the optimal level of capital. The left hand side is the shadow price of one unit of newly installed capital for all firms (since $\left.\lambda_{t}=\frac{1}{\varepsilon_{t}^{*}}\right)$. The right hand side has three components. First, one unit of newly installed capital can generate $R_{t+1}$ units of cash flow tomorrow with an option value of $R_{t+1} Q_{t+1}$. Second, this unit of capital has a residual equity value of $\frac{1-\delta}{\varepsilon_{t+1}^{*}}$ after depreciation in the next period. Third, one additional unit of capital allows the firm to raise $\frac{\theta}{r_{t+1}}$ additional units of external funds, which amounts to an additional cash value of $\frac{\theta}{r_{t+1}}\left(Q_{t+1}-1\right)$, where $Q_{t+1}-1$ is the net option value of borrowing. The net option value applies here because borrowing must involve repayment. Hence, the right-hand side of equation (27) measures the expected gains from having one unit of newly installed capital, which by arbitrage must equal the shadow price on the left-hand side. Because both the shadow price and the expected marginal gains of new capital depend 
on the probability of undertaking investment (i.e., the cutoff), equation (27) also determines the optimal cutoff $\varepsilon_{t}^{*}$.

The cutoff $\varepsilon_{t}^{*}$ divides all firms into two groups in each period: active firms (making fixed investments) and inactive firms (not investing). When $\varepsilon_{t}(i) \geq \varepsilon_{t}^{*}$, investing in fixed capital is strictly profitable, so firms are willing to exhaust all available funds to finance fixed investment. This implies that active firms pay no dividends and borrow up to the borrowing limit $b_{t+1}(i)=$ $\theta k_{t}(i)$. Inactive firms which are suffering unfavorable shocks $\left(\varepsilon_{t}^{*}(i)<\varepsilon_{t}^{*}\right)$, however, decide not to invest in fixed capital but opt instead to invest in the bond market, lending a portion of their cash flows to productive firms.

Corollary 1 The equilibrium interest rate of bonds is determined by

$$
\frac{1}{r_{t}}=\beta E_{t} \frac{\Lambda_{t+1}}{\Lambda_{t}} Q\left(\varepsilon_{t+1}^{*}\right) .
$$

\section{Proof. See Appendix I.B.}

Equation (29) holds because for an inactive firm that decides to lend (buy bonds), saving one dollar today yields $r_{t}$ dollars tomorrow, which has an option value of $Q_{t+1}$. Hence, $1=$ $\beta E_{t}\left[\frac{\Lambda_{t+1}}{\lambda_{t}} r_{t} Q_{t+1}\right]$. Notice that at steady state $r<\frac{1}{\beta}$ (as in Cooley and Quadrini, 2001) because $Q\left(\varepsilon^{*}\right)>1$. This helps to explain the low risk-free rate puzzle much discussed in the asset pricing literature. In addition, this implies that households will not hold bonds under these assumptions because they (unlike firms) do not benefit from the liquidity value of bonds.

Notice that if $Q_{t}=1$ for all $t$, then equation (27) is reduced to a standard neoclassical equation for investment. This would be the case if there were no idiosyncratic shocks in our model. That is, the option value $Q_{t}>1$ is a consequence of idiosyncratic shocks and irreversible investment, which generate a demand for liquidity and induce firms to postpone investment when they are suffering bad shocks. ${ }^{23}$

Equations (27) and (26) are key to understanding the implications of the model. Equation (26) shows that optimal investment at the firm level is proportional to the firm's existing stock of capital $k_{t}(i)$ if we ignore $b_{t}(i)$, with the proportionality depending on $\left[R_{t}+\frac{\theta}{r_{t}}\right]$. This has the following implications:

\footnotetext{
${ }^{23}$ Notice that the constraint $i_{t} \geq 0$ does not bind with respect to aggregate shocks if the support of idiosyncratic shocks is $[0, \infty]$. In this case it is impossible for all firms to have zero investment in the same period regardless of how low the aggregate productivity shock is, because there is always a positive fraction of firms with large enough $\varepsilon(i)$ to undertake fixed investment. Hence, irreversible investment matters only with respect to idiosyncratic shocks. In this regard, the option value $Q>1$ implicitly reflects irreversible investment.
} 
1) The volatility and lumpiness of firm-level investment increases with $\theta$ because $\left(R_{t}+\frac{\theta}{r_{t}}\right)$ measures the responsiveness of a firm's investment rate (or investment-to-capital ratio) to its idiosyncratic shocks. Clearly, the larger the value of $\theta$, the higher the investment rate or the investment-to-capital ratio when the firm opts to invest. This suggests that as $\theta$ increases, investment is more volatile at the firm level. In addition, as will be shown in the next section, the cutoff value increases with $\theta$ (i.e., $\frac{d \varepsilon^{*}}{d \theta}>0$ ). Hence, the probability that a firm undertakes capital investment decreases as $\theta$ increases (because $i_{t}(i)>0$ if and only if $\varepsilon(i)>\varepsilon^{*}$ ). This suggests that a firm invests relatively less frequently with a larger $\theta$. (Though if a firm undertakes any fixed investment, it will invest a larger amount.) Hence, FD makes firm-level investment lumpier and more volatile.

2) Because aggregate shocks affect firms' investment through internal cash flow (i.e., through the function $R_{t}$ ), aggregate investment $\int_{0}^{1} i(i) d i$ responds less to aggregate shocks when $\theta$ is larger, because internal cash flow becomes less important for investment financing when external funds are available. Therefore, the variability of aggregate employment (as well as output) is reduced by FD. Furthermore, because FD promotes investment efficiency by enabling more efficient risk sharing and credit-resource allocation among firms, the aggregate number of active firms decreases with $\theta$. This further reduces the responsiveness of aggregate investment to technology shocks along the extensive margin.

\subsection{Aggregation}

Assume a constant-returns-to-scale CES production function, $y_{t}(i)=\left\{\alpha k_{t}^{\sigma}(i)+(1-\alpha)\left[A_{t} n_{t}(i)\right]^{\sigma}\right\}^{\frac{1}{\sigma}}$, with $\alpha \in(0,1)$ and $\sigma \in(-\infty, 1)$. The labor demand equation (16) then becomes

$$
(1-\alpha)\left(\frac{y_{t}(i)}{n_{t}(i)}\right)^{1-\sigma} A_{t}^{\sigma}=w_{t}
$$

or $(1-\alpha)\left\{\alpha\left[\frac{k_{t}(i)}{n_{t}(i)}\right]^{\sigma}+(1-\alpha) A_{t}^{\sigma}\right\}^{\frac{1-\sigma}{\sigma}} A_{t}^{\sigma}=w_{t}$

Proposition 2 Define aggregate capital $K_{t}=\int k_{t}(i) d i$, aggregate labor demand $N_{t}=\int n_{t}(i) d i$, aggregate output $Y_{t}=\int y_{t}(i) d i$, and aggregate investment expenditure $I_{t}=\int i_{t}(i) d i$. The model's equilibrium can be characterized in terms of the nine aggregate variables $\left\{I_{t}, C_{t}, Y_{t}\right.$, 
$\left.N_{t}, R_{t}, \varepsilon_{t}^{*}, r_{t}, w_{t}, K_{t+1}\right\}$, which can be solved by using the system of nine nonlinear equations:

$$
\begin{gathered}
\frac{\Omega_{c t}}{\varepsilon_{t}^{*} C_{t}}=\beta E_{t} \frac{\Omega_{c t+1}}{C_{t+1}}\left\{R_{t+1} Q\left(\varepsilon_{t+1}^{*}\right)+\frac{\theta}{r_{t+1}}\left[Q\left(\varepsilon_{t+1}^{*}\right)-1\right]+\frac{(1-\delta)}{\varepsilon_{t+1}^{*}}\right\} \\
\frac{1}{r_{t}} \frac{\Omega_{c t}}{C_{t}}=\beta E_{t} \frac{\Omega_{c t+1}}{C_{t+1}} Q\left(\varepsilon_{t+1}^{*}\right) \\
C_{t}+G_{t}+I_{t}=Y_{t} \\
Y_{t}=\left\{\alpha K_{t}^{\sigma}+(1-\alpha)\left[A_{t} N_{t}\right]^{\sigma}\right\}^{\frac{1}{\sigma}} \\
I_{t}=\left(R_{t}+\frac{\theta}{r_{t}}\right) K_{t}\left[1-F\left(\varepsilon_{t}^{*}\right)\right] \\
K_{t+1}=(1-\delta) K_{t}+P\left(\varepsilon_{t}^{*}\right) I_{t} \\
\frac{w_{t}}{C_{t}}=\Omega_{n t} N_{t}^{\gamma} \\
w_{t}=(1-\alpha)\left(\frac{Y_{t}}{N_{t}}\right)^{1-\sigma} A_{t}^{\sigma} \\
R_{t}=\alpha\left(\frac{Y_{t}}{K_{t}}\right)^{1-\sigma}
\end{gathered}
$$

where $Q\left(\varepsilon_{t}^{*}\right) \equiv \int \max \left\{\frac{\varepsilon}{\bar{\varepsilon}_{t}^{*}}, 1\right\} d F(\varepsilon)$ and $P\left(\varepsilon_{t}^{*}\right) \equiv\left[\int_{\varepsilon \geq \varepsilon_{t}^{*}} \varepsilon d F(\varepsilon)\right]\left[1-F\left(\varepsilon_{t}^{*}\right)\right]^{-1}$.

\section{Proof. See Appendix II.}

Equation (31) is identical to equation (27). Equation (32) is the same as equation (29). Equation (33) is the aggregate resource constraint. Equation (34) can be derived by aggregating the production functions of all firms (constant returns to scale imply that the aggregate production function is identical to a single firm's production function). Equation (35) is derived from equation (26). Equation (36) is the law of motion for the aggregate capital stock. Equation (37) is based on the first-order conditions for a household. Finally, equations (38) and (39) relate the real wage rate and the marginal product of capital based on the output-to-labor ratio and the output-to-capital ratio, respectively. 


\subsection{Steady State}

A steady state is defined as a situation in which there is no aggregate uncertainty (i.e., $A_{t}=$ $\Omega_{c t}=\Omega_{n t}=1$ and $\frac{G_{t}}{Y_{t}}=$ constant) and the distributions of the firm-level variables are timeinvariant (notably, the cutoff $\varepsilon^{*}$ is constant).

Proposition 3 The model has a unique steady state. At steady state, the cutoff $\varepsilon^{*}$ is the solution to the following equation:

$$
\frac{1}{\varepsilon^{*} Q\left(\varepsilon^{*}\right)}[1-\beta(1-\delta)]=\beta\left[\frac{\delta}{\left[\int_{\varepsilon \geq \varepsilon^{*}} \varepsilon d F(\varepsilon)\right]}-\beta \theta\right]
$$

Given $\varepsilon^{*}$, the steady-state ratios $\left\{\frac{Y}{K}, \frac{I}{Y}, \frac{Y}{C}, \frac{Y}{N}\right\}$ satisfy

$$
\begin{gathered}
\alpha\left(\frac{Y}{K}\right)^{1-\sigma}=\frac{1}{\varepsilon^{*}}\left[\frac{1}{\beta}-1\right]+\frac{\delta}{\left[1-F\left(\varepsilon^{*}\right)\right]^{-1} \int_{\varepsilon \geq \varepsilon^{*}} \varepsilon d F(\varepsilon)} \\
\frac{I}{Y}=\left[R+\frac{\theta}{r}\right]\left[1-F\left(\varepsilon^{*}\right)\right]\left(\frac{\alpha}{R}\right)^{\frac{1}{1-\sigma}}=1-\frac{C}{Y}-\frac{G}{Y} \\
\frac{Y}{C}\left[1-\alpha\left(\frac{R}{\alpha}\right)^{\frac{\sigma}{\sigma-1}}\right]=N^{1+\gamma} \\
Y=\left[\frac{1-\alpha}{1-\alpha\left(\frac{R}{\alpha}\right)^{\frac{\sigma}{\sigma-1}}}\right]^{\frac{1}{\sigma}} N,
\end{gathered}
$$

and the real prices $\{r, w, R\}$ satisfy $r=\frac{1}{\beta Q\left(\varepsilon^{*}\right)}, w=(1-\alpha)\left(\frac{Y}{N}\right)^{1-\sigma}$, and $R=\alpha\left(\frac{Y}{K}\right)^{1-\sigma}$.

Proof. See Appendix III.A.

Corollary 2 For any distribution of $\varepsilon$, the following comparative statics hold:

$$
\frac{\partial \varepsilon^{*}}{\partial \theta}>0, \quad \frac{\partial Q}{\partial \theta}<0, \quad \frac{\partial r}{\partial \theta}>0, \quad \frac{\partial P}{\partial \theta}>0, \quad \text { and } \frac{\partial R}{\partial \theta}<0 .
$$

In addition, as long as capital and labor are not perfect substitutes in the production function 
$(\sigma<1)$, we have

$$
\frac{\partial w}{\partial \theta}>0, \quad \frac{\partial(Y / N)}{\partial \theta}>0, \quad \frac{\partial(K / N)}{\partial \theta}>0, \quad \text { and } \frac{\partial(Y / K)}{\partial \theta}<0
$$

Proof. See Appendix III.B.

FD promotes better risk sharing among firms. It allows the productive firms to invest more by borrowing more and the less productive firms to save with a higher interest rate. Therefore, FD means that the probability of undertaking capital investment $\left(\operatorname{Pr}\left(\varepsilon>\varepsilon^{*}\right)\right)$ is reduced $\left(\frac{\partial \varepsilon^{*}}{\partial \theta}>0\right)$, making firm-level investment lumpier. This reduction in probability also reduces the option value of cash flow $\left(\frac{d Q}{d \varepsilon^{*}}<0\right)$, equation (32) then implies that the rate of return on bonds increases $\left(\frac{\partial r}{\partial \theta}>0\right)$. In other words, FD increases the aggregate rate of return on investment projects by redirecting funds away from the less productive investment opportunities toward more productive ones, thus raising the competitive interest rate $r_{t}$ in the bond market to reward savings. Consequently, less productive firms are better off through saving (holding bonds) rather than investing inefficiently in fixed capital, allowing the more productive firms to invest more in fixed capital by raising external funds from less productive firms. Finally, $\frac{\partial P}{\partial \theta}>0$ implies that the aggregate investment efficiency is improved even though fewer firms are investing (similar to the model of Greenwood et al. 2007). That is, the economy accumulates more capital despite there being fewer firms are undertaking fixed investment because the active (more productive) firms can invest more intensively and with a higher marginal efficiency. Because of diminishing returns to capital, it must be true that $\frac{\partial R}{\partial \theta}<0$. Since the return on fixed capital decreases and the return on bonds increases, FD reduces the spread of returns across firms and thus indicates better risk sharing among firms. ${ }^{24}$

Finally, the improved investment efficiency has important implications for the real wage. Since $\frac{\partial R}{\partial \theta}<0$, FD increases the aggregate capital-to-output ratio and the aggregate capital-tolabor ratio, which is consistent with the analysis of Greenwood, Sanchez, and Wang (2007). Hence, the real wage increases with FD $\left(\frac{\partial w}{\partial \theta}>0\right)$.

\subsection{Calibration}

Let the time period be one quarter, the time discount rate $\beta=0.99$, the rate of capital depreciation $\delta=0.025$, and the inverse labor supply elasticity $\gamma=0$ (indivisible labor). A large

\footnotetext{
${ }^{24}$ The spread between the interest rate in the bond market and the household discounting factor $(1 / \beta)$ also declines with FD.
} 
segment of the empirical literature shows that the aggregate production function is not exactly Cobb-Douglas. Instead, it is CES with the elasticity of substitution parameter $\sigma>0$ (see Duffy and Papageorgiou, 2000; Masanjala and Papageorgiou, 2004). The empirical estimates of $\sigma$ range from 0.1 to 0.6 , with an average around 0.2 . Thus, we set $\sigma=0.2$ and choose $\alpha=0.25$ so that the implied steady-state income share of capital is about 0.42 when $\theta \approx 0$ (our benchmark value). ${ }^{25}$ The laws of motion for aggregate shocks are assumed to follow stationary $\mathrm{AR}(1)$ processes,

$$
\begin{aligned}
\log A_{t} & =\rho \log A_{t-1}+\varepsilon_{A t} \\
\log \Omega_{c t} & =\rho \log \Omega_{c t-1}+\varepsilon_{c t} \\
\log \Omega_{n t} & =\rho \log \Omega_{n t-1}+\varepsilon_{n t} \\
\log G_{t} & =\rho \log G_{t-1}+\varepsilon_{g t},
\end{aligned}
$$

where the common persistence parameter $\rho=0.9$ and the innovations are orthogonal to each other.

Assume that the firm-specific shock $\varepsilon$ follows the Pareto distribution $F(\varepsilon)=1-\varepsilon^{-\eta}$ with $\varepsilon \in(1, \infty)$ and $\eta>0$. We set the shape parameter $\eta=3.0$ so that the order of magnitude of firm-level volatility in our model is consistent with the U.S. data. These parameter values are summarized in Table 1.

Table 1. Parameter Values

\begin{tabular}{cccccccc}
\hline \hline Parameter & $\beta$ & $\delta$ & $\gamma$ & $\eta$ & $\sigma$ & $\alpha$ & $\rho$ \\
Value & 0.99 & 0.025 & 0 & 3.0 & 0.2 & 0.25 & 0.9 \\
\hline
\end{tabular}

The most important and interesting parameter of the model is $\theta$. We vary the value of $\theta$ to demonstrate the effects of FD on aggregate volatility. In the U.S. economy, the total private debt-to-GDP ratio of nonfinancial firms (as measured by FD2 - claims on private sectors) has doubled from about $23 \%$ to $48 \%$ over the past 50 years. In our model, the implied steady-state aggregate debt-to-output ratio is $24 \%$ when $\theta=0.05$ and $48 \%$ when $\theta=1.5$. Hence, we will vary the value of $\theta$ within the interval $[0,1.5]$ in the following experiments, to demonstrate how credit generation and reallocation alone can render a less developed country (with zero private debt) significantly less volatile if its private debt reaches the U.S. level.

\footnotetext{
${ }^{25}$ Assuming a Cobb-Douglas production function $(\sigma=0)$ yields qualitatively similar results. However, the negative effects of financial development on aggregate volatility are stronger if $\sigma>0$.
} 


\section{$5 \quad$ Explaining Cross-County Aggregate Volatility}

Figure 6 shows the responses of aggregate output, consumption, investment, and employment to a $1 \%$ positive aggregate technology shock, where the solid line in each panel represents the case with $\theta=0$ and the dot-dashed line represents the case with $\theta=1.5$.
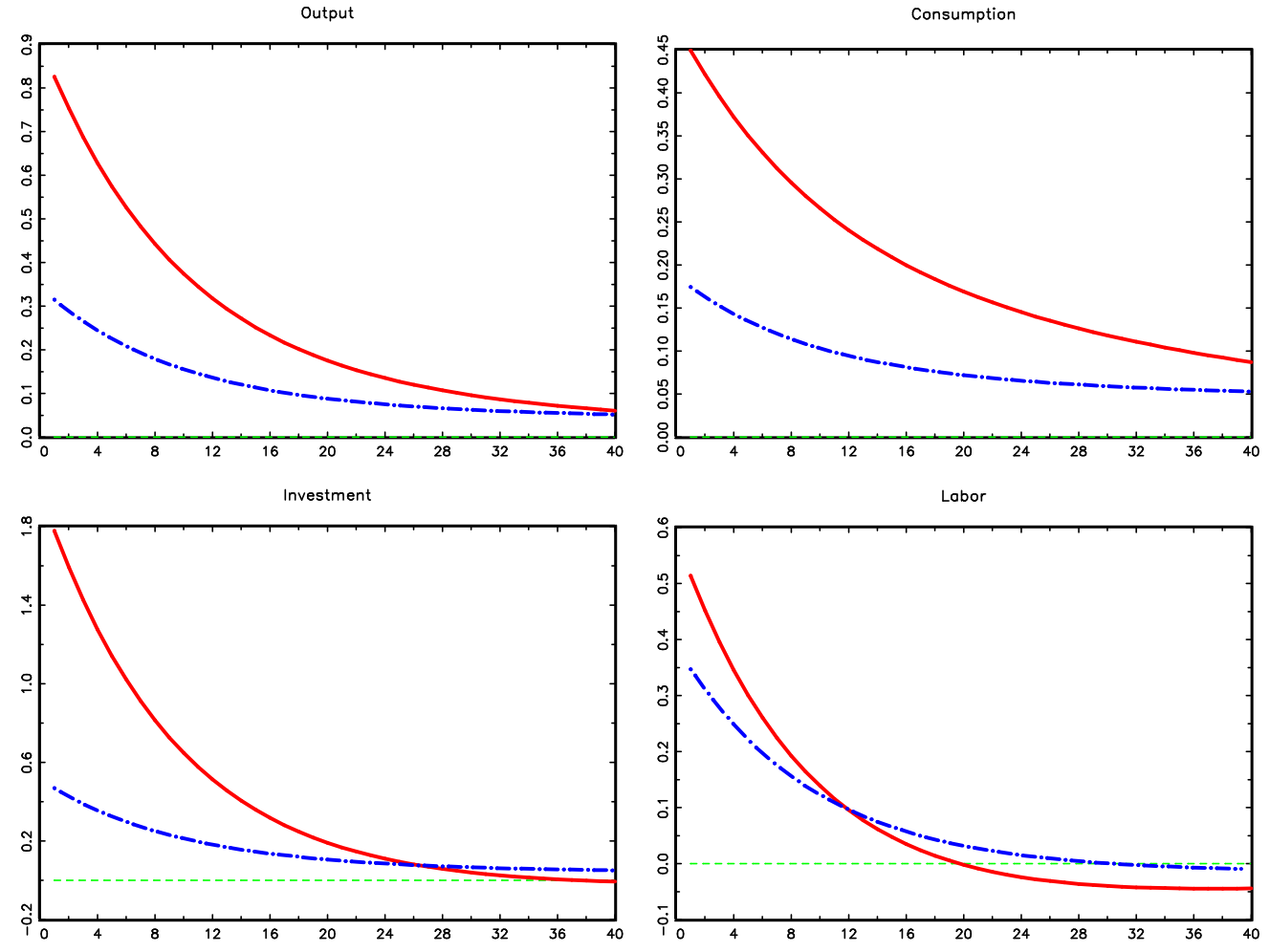

Figure 6. Impulse Responses to $A_{t}$ Shock (solid line: $\theta=0.05$; dashed line: $\theta=1.5$ ).

The figure shows that with sufficient financial development, a country's aggregate output, consumption, investment and employment can all become significantly less volatile under the same magnitude of technology shock. For example, the variance of output growth reduces by $86 \%$, consumption growth by $85 \%$, investment growth by $93 \%$, and employment growth by $55 \%$ as the value of $\theta$ increases from 0 to 1.5.

However, a segment of the business-cycle literature has argued that technology shock may not be the only or the most important shock driving the business cycle. ${ }^{26}$ Therefore, it is critical that our model can also generate similar reductions in aggregate volatility under non-technology shocks. The most popular non-technology shocks considered in this literature include (i) shocks

\footnotetext{
${ }^{26}$ See Bai, Rios-Rull, and Storesletton (2011), Benhabib and Wen (2004), Blanchard (1989), Christiano and Eichenbaum (1992), Christiano, Eichenbaum, and Evans (2005), Cochrane (1994), Eichenbaum (1991), Evans (1992), Galí and Rabanal (2004), Mankiw (1989), Smets and Wouters (2003), Summers (1986), Wen (2004, 2005), among many others.
} 
to the marginal utility of leisure, (ii) shocks to the marginal utility of consumption, and (iii) shocks to government expenditures.

Table 2 reports the reductions in the variance of output growth under various types of aggregate demand shocks. In simulating the model, we have set the steady-state government spending-to-GDP ratio $\frac{G}{Y}=0.2$ under all shocks, consistent with the postwar U.S. data. The table shows that when the private debt-to-GDP ratio increases from $0 \%$ to $48 \%$ (i.e., $\theta$ increases from 0 to 1.5), the variance of output growth is reduced by $84 \%$ under shocks to the marginal utility of leisure, by $95 \%$ under shocks to the marginal utility of consumption, and by $86 \%$ under government spending shocks. The results are robust to the persistence of the shocks. For example, the lower panel of Table 2 shows that the reductions in GDP volatility are equally significant under various types of highly persistent aggregate shocks (i.e., $\rho=0.99) .{ }^{27}$

\begin{tabular}{ccccc}
\multicolumn{4}{c}{ Table 2. Reduction in Variance of GDP Growth $\left(\sigma_{\Delta \log Y_{t}}^{2}\right)$} \\
\hline \hline & $A_{t}$ Shock & $\Omega_{c t}$ Shock & $\Omega_{n t}$ Shock & $G_{t}$ Shock \\
$\rho=0.9$ & $84 \%$ & $95 \%$ & $84 \%$ & $86 \%$ \\
$\rho=0.99$ & $83 \%$ & $89 \%$ & $83 \%$ & $72 \%$ \\
\hline
\end{tabular}

Several forces are at work for FD to reduce aggregate (especially investment) volatility under aggregate shocks. First, aggregate shocks affect investment primarily through their effects on firms' operating profits (i.e., the revenue function $R_{t}$ ). With the development of the financial markets, firms are able to finance their investments more intensively through external borrowing. Equation (35) or (26) predicts that firms' internal cash flow $\left(R_{t}\right)$ becomes less important relative to external debt $\left(\frac{\theta}{r_{t}}\right)$, which leads to a reduction in the responsiveness of firmlevel investment to aggregate technology shocks (a decline in aggregate investment volatility along the intensive margin). Second, FD makes firm-level investment lumpier. Since the number of active firms making fixed investments decreases with $\theta\left(\frac{\partial}{\partial \theta}\left[1-F\left(\varepsilon^{*}\right)\right]<0\right.$ because $\left.\frac{\partial \varepsilon^{*}}{\partial \theta}>0\right)$, equation (35) implies that the response of aggregate investment to a technology shock is smaller along the extensive margin. Third, FD improves investment efficiency. Hence, capital becomes cheaper relative to labor and firms opt to use more and more capital in production relative to labor. As a result, the real wage will increase and labor will play a shrinking role in production. This effect suggests that aggregate shocks that primarily affect labor demand (such as preference

\footnotetext{
${ }^{27}$ With $\frac{G}{Y}=0.2$, the volatility reduction is slightly different (smaller) than the case with $\frac{G}{Y}=0$. It is interesting to note that $\Omega_{n t}$ shock (i.e., the labor supply shock) is identical to technology shock in terms of its impact on output. It can be easily proven that the two shocks indeed have identical effects on aggregate output in our model.
} 
shocks and government spending shocks) will have a smaller impact on output as $\theta$ increases, leading to a decline in aggregate volatility.

An interesting pattern of the cross-country data revealed by Easterly, Islam, and Stiglitz (2000) and this paper in Section 2 is the diminishing effect of FD on aggregate volatility. This diminishing effect is also well captured by our model. For example, the left panel in Figure 7 shows that the variance of GDP growth in our model decreases as $\theta$ increases and it does so at a diminishing rate, regardless of the sources of aggregate shocks. The volatility-reducing effect of FD is most strong on preference shocks to consumption demand (dot-dashed line).
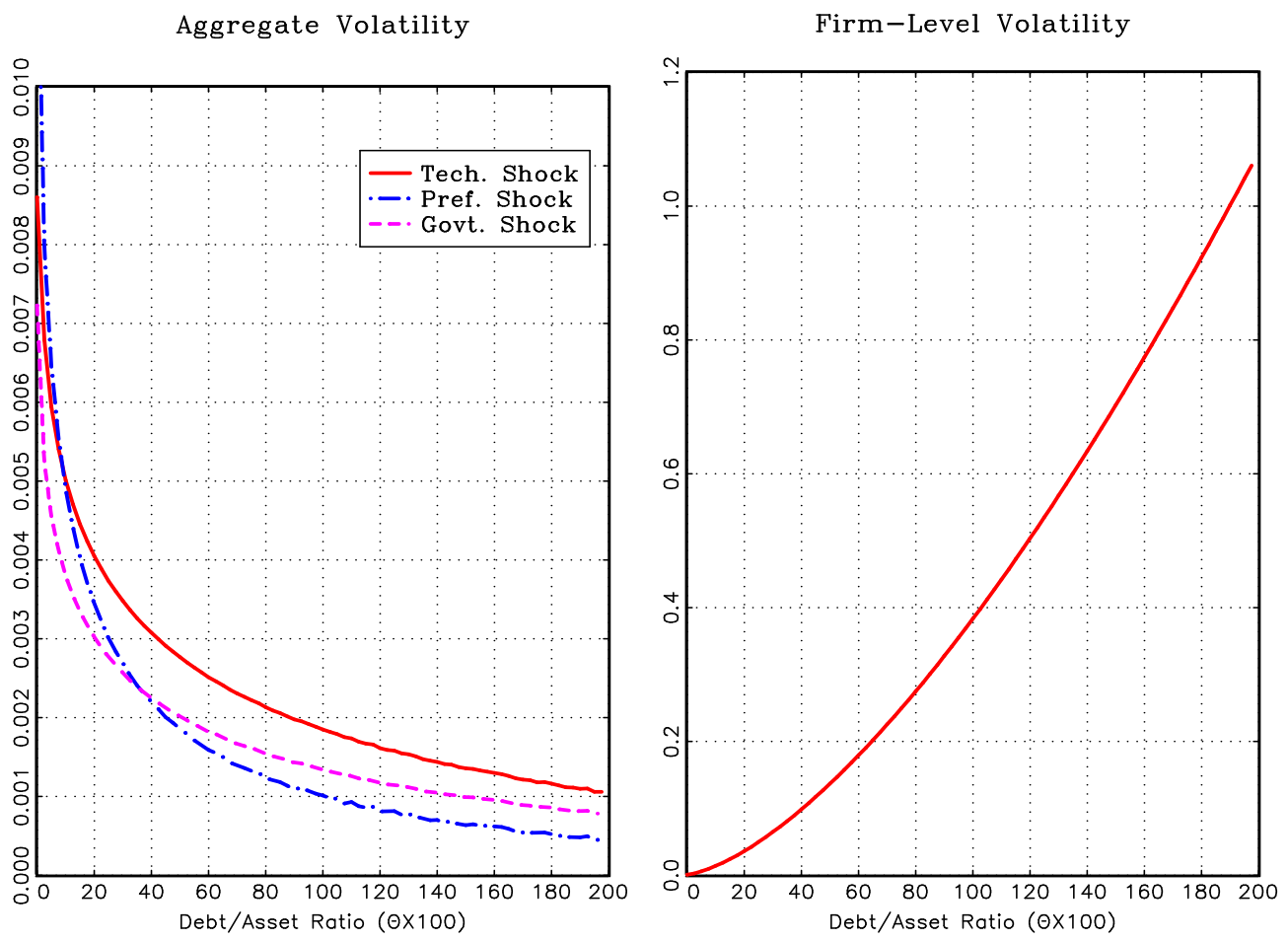

Figure 7. Effects of FD on Aggregate and Firm-Level Volatility.

The intuition behind the diminishing effect of FD on aggregate volatility is as follows. There are two margins through which aggregate investment can respond to aggregate shocks. On the intensive margin, the volatility of aggregate investment decreases with $\theta$ because each firm is less dependent on internal cash flows when $\theta$ increases. On the extensive margin, since a higher value of $\theta$ increases firms' leverage, it raises the sensitivity of investment returns to favorable cash-flow shocks. This implies that more firms are willing to undertake investment under a positive shock to the cash flow. These two margins can be seen in equation (35). The intensive margin of aggregate investment is captured by the first term $\left(R_{t}+\frac{\theta}{r_{t}}\right)$ whereas the extensive margin is captured by the second term $\left[1-F\left(\varepsilon_{t}^{*}\right)\right]$. The extensive margin serves as a 
counter-force to the intensive margin, hence dampening the stabilizing effect of FD on aggregate volatility. Since the effect of this counter-force grows with $\theta$, the curves (left panel in Figure 7) show an L-shaped convex (diminishing) pattern.

At the aggregate level, an additional prediction of our model is worth emphasizing: The marginal cost of new capital goods in our model declines with financial liberalization even without "investment-specific" technological progress. Greenwood, Hercowitz, and Krusell (1997) document a steady decline in the relative price of investment goods (e.g., equipment) in the U.S. This stylized fact has been attributed by the existing literature to changes in "investment-specific" technology. This technology is typically modeled by the variable $z_{t}$ in the capital accumulation equation

$$
K_{t+1}=(1-\delta) K_{t}+z_{t} I_{t}
$$

Since $z_{t}$ is assumed to be growing over time by Greenwood, Hercowitz, and Krusell (1997), the productivity of investment rises and the marginal cost of new capital goods falls. Our model can generate the same pattern of a declining price of investment goods without assuming "investment-specific" technology changes. In our model, $z_{t}$ is replaced by an endogenous variable $P\left(\varepsilon_{t}^{*}\right)$ (see equation (36)), which measures the efficiency of aggregate investment and rises with FD. So as $\theta$ increases, the marginal cost of new capital goods in our model $\left(\frac{1}{\varepsilon^{*}}\right)$ also decreases $\left(\right.$ since $\left.\frac{\partial \varepsilon^{*}}{\partial \theta}>0\right) .^{28}$

\section{Explaining Firm-Level Volatility Changes}

Empirical studies have shown that the volatility of publicly traded firms has been increasing over the postwar period in the U.S. and other OECD countries. We believe that this trend is driven by financial liberalization.

This belief is supported by the empirical evidence that firm-level volatility is positively correlated with leverage. For example, Table 3 shows that a firm's leverage $\left(l_{t}\right)$, defined as the ratio of total debt to total assets, is significantly correlated with the standard deviation (SD) of sales growth $\left(\Delta s_{t}\right)$ and asset growth $\left(\Delta a_{t}\right)$ in various industries. The first column shows the correlation between leverage and the SD of sales growth, and the second column

\footnotetext{
${ }^{28}$ Models with aggregate investment have to resort to capital- or investment adjustment costs to capture proper investment dynamics. Here there are no such costs but we match the aggregate investment behavior well because of lumpy investment at the firm level. As explored and explained in Wang and Wen (2012), irreversible investment and borrowing constraints provide a micro foundation for aggregate adjustment costs. The intuition is that with these micro frictions, investment has a large option value, so firms opt to wait for better opportunities to invest, making investment lumpy at the firm level. This lumpiness at firm level also implies that firms need to borrow (or need other external finance) to invest. Since borrowing requires capital as collateral, the aggregate investment is tied to the aggregate capital stock. These mechanisms show up at the aggregate level like aggregate adjustment costs.
} 
shows the correlation with respect to the SD of asset growth. The first column indicates that for most industries (except Construction) the correlation is significantly positive, with Chemicals, Fabricated Metal Products, Public Administration, and Retail Trade having the highest correlation, ranging from 0.42 to 0.47 . The average correlation for the 17 industries is 0.27 (with SD 0.136). The average correlation is even stronger if volatility is measured by the SD of asset growth (column 2).

Table 3. Correlation between Leverage and Firm Volatility

\begin{tabular}{lcc}
\hline \multicolumn{1}{c}{ Industry } & $\operatorname{corr}\left(l_{t}, S D\left(\Delta s_{t}\right)\right)$ & $\operatorname{corr}\left(l_{t}, S D\left(\Delta a_{t}\right)\right)$ \\
Wholesale Trade & 0.31 & 0.42 \\
Textiles & 0.34 & 0.40 \\
Steel & 0.21 & 0.45 \\
Services & 0.34 & 0.29 \\
Retail Trade & 0.42 & 0.43 \\
Public Administration & 0.43 & 0.57 \\
Oil & 0.14 & 0.29 \\
Mining & 0.20 & 0.16 \\
Material & 0.20 & 0.40 \\
Food & 0.23 & 0.26 \\
Fabricated Metal Products & 0.44 & 0.39 \\
Electronic Equipment & 0.35 & 0.31 \\
Construction & -0.05 & 0.04 \\
Chemicals & 0.47 & 0.45 \\
Transportation Equipment & 0.22 & 0.44 \\
Business Equipment & 0.28 & 0.31 \\
Agriculture & 0.08 & -0.16 \\
\multicolumn{1}{c}{ Mean } & 0.27 & 0.32 \\
\cline { 3 - 3 } & 0.136 & 0.175 \\
\hline
\end{tabular}

Source: Compustat. $l_{t}$ : debt-to-asset ratio; $\Delta s_{t}$ : sales growth; $\Delta a_{t}$ : asset growth.

The rising trend in firm-level volatility and the positive correlation between leverage and firm-level volatility are as predicted by our model. Note that because $\varepsilon_{t}(i)$ are i.i.d., the measure of firm-level volatility based on a time series is identical to the dispersion of firm-level activities across firms in our model. Hence, following Comin and Philippon (2005), we can assess the firm-level volatility in the model using the SD (or variance) of the median firm's sales growth. The constant returns to scale production function implies that a firm's sales (output) and labor 
are proportional to its capital stock, so that the capital growth rate $g_{t}(i)=\frac{k_{t+1}(i)}{k_{t}(i)}-1$ can be used as the measure. ${ }^{29}$ Because the median firm's debt level is zero in the model economy, we set $b_{t}(i)=0$ in computing $g_{t}(i)$. Noting that $\left(R+\frac{\theta}{r}\right)=\frac{\delta}{P[1-F]}$ at steady state (see equations 69 and 70), the firm-level growth rate is given by

$$
g_{t}(i)=\left\{\begin{array}{cl}
-\delta & \text { if } \varepsilon_{t}(i) \leq \varepsilon^{*} \\
-\delta+\left[\delta\left(\frac{\eta-1}{\eta}\right) \varepsilon^{* \eta-1}\right] \varepsilon_{t}(i) & \text { if } \varepsilon_{t}(i)>\varepsilon^{*}
\end{array} .\right.
$$

Notice that the mean growth rate is zero, $\bar{g}(i)=E g_{t}(i)=0$, because it is the same as the aggregate capital growth rate in the steady state $\left(\frac{K_{t+1}}{K_{t}}-1=0\right) \cdot{ }^{30}$ Hence, the SD of the growth rate is

$$
\sigma_{g}=\sqrt{E g_{t}^{2}(i)}=\delta \sqrt{\frac{(\eta-1)^{2}}{\eta(\eta-2)} \varepsilon^{* \eta}-1}
$$

Because $\frac{d \varepsilon^{*}}{d \theta}>0$, the model implies that firm-level volatility increases with FD.

In the U.S. data, firm-level volatility is about ten times the aggregate volatility. Given that the variance of idiosyncratic shocks dominates that of aggregate shocks in both the data and our model, ignoring aggregate uncertainty in computing $\sigma_{g}$ does not significantly affect the measured firm-level volatility. The predicted trend in firm-level volatility is plotted in the right panel of Figure 7, where the horizontal axis pertains to FD and the vertical axis is the variance of sales growth of the median firm in our model. It shows that the firm-level volatility trends up as the financial market develops, consistent with the empirical facts documented in the existing literature and in Table 3.

\section{Further Robustness Analyses}

Although we have documented a robust non-linear negative relationship between FD and aggregate volatility and provided a theoretical model to illustrate a plausible causal link from FD

\footnotetext{
${ }^{29}$ Similar results hold if we measure firm-level volatility by the variance of the return to firms' equities or firm values.

${ }^{30}$ This can be confirmed by computing the true average growth rate

$$
\bar{g}(i)=-\delta+\delta\left(\frac{\eta-1}{\eta}\right) \varepsilon^{* \eta-1} \int_{\varepsilon^{*}}^{\infty} \varepsilon f(\varepsilon) d \varepsilon=0 .
$$

Notice that the growth rate has zero mean, so it capture the short-run variations in the model. This is consistent with our previous studies where time trends are absent in the analysis.
} 
to aggregate volatility, a legitimate concern (among others) is whether the observed smaller aggregate volatility for financially more developed countries may be driven instead by smaller aggregate shocks rather than better FD. To address such a concern, this section conducts a quantitative analysis. The analysis is a country-by-country estimation of the FD parameters $\{\eta, \theta\}$ and other key structural parameters in our model, such as parameters governing the aggregate shocks in each country. When each country's aggregate data are best matched by our model under the estimation, we then ask if the estimated FD parameter $\theta$ is indeed negatively correlated with the GDP volatility observed in the data or implied by the model, after aggregate shocks are controlled for. In this way we can quantitatively address the following question: Given the estimated aggregate shock processes hitting each country that best explain the country's aggregate volatility, do the data indeed favor a higher estimated value of $\theta$ (better FD) for less volatile countries than more volatile ones? If the answer is yes, then it provides additional quantitative support for our theory because the negative relationship holds even when the underlying aggregate shocks and their contributions to GDP volatility are fully taken into account.

We use Bayesian method in our estimation. A challenge in Bayesian estimation is to set the priors of the distribution of so many parameters. We choose to use the U.S. economy as our benchmark. In principle, we could simply calibrate all of the U.S. parameters and use the information to set our priors for the other OECD countries. However, we try to be more sophisticated; namely, we calibrate only the standard parameters for the U.S. economy and estimate the remaining ones by Bayesian method (unless data are readily available for calibration). After obtaining U.S. parameter values, for each remaining OECD country our model is estimated to maximize the posterior likelihood of the standard deviation of four growth rates in per capita terms: real GDP, real consumption, real investment, and hours worked per week. $^{31}$ Data Appendix V (Online Appendix A) provides details about the data.

To proceed, we first discuss how to obtain parameters values for the U.S. economy. We then conduct country-by-country estimation for other OECD countries, using the information of U.S. parameter values to set our priors.

\subsection{The U.S. Economy}

For the U.S. economy, we partition the structural parameters in the model into three sets. The first set, $\Theta_{1}^{U S}=\left\{\beta, \delta, \sigma, \gamma, \frac{G}{Y}\right\}$, contains standard parameters, so they are not essential for

\footnotetext{
${ }^{31}$ We use these aggregate variables to reflect the impact of multiple aggregate shocks on the economy. For some countries where hours worked per week are not available, we use hours worked per month or quarterly employment as a proxy. Because of the lack of quarterly data for employment for developing countries, we focus on OECD countries in this particular analysis.
} 
our question and are thus calibrated according to Table 1 (we set the steady-state government spending to GDP ratio $\left.\frac{G}{Y}=0.2\right)$

The second parameter set $\Theta_{2}^{U S}=\left\{\eta, \rho_{\kappa}, \sigma_{\kappa}, \sigma_{\varepsilon}^{m e}\right\}$, where the index $\kappa=\left\{A, \Omega_{c}, \Omega_{n}, \Omega_{G}\right\}$ refers to the four aggregate shocks. This set contains the shape parameter $(\eta)$ in the Pareto distribution (which controls the dispersion of the idiosyncratic shocks to firm investment), the parameters governing the shock processes $\left\{\rho_{\kappa}, \sigma_{\kappa}\right\}$, as well as the standard deviation of a measurement error, $\sigma_{\varepsilon}^{m e}$ (see discussions below for details). We estimate the parameters in $\Theta_{2}^{U S}$ via Bayesian method based on U.S. quarterly data (1975Q1 to 2014Q4). Following SchmittGrohe and Uribe (2012), we add a measurement error to the output growth, $\varepsilon_{t}^{m e}$, which is i.i.d with mean zero and standard deviation $\sigma_{\varepsilon}^{m e} \cdot{ }^{32}$

Table 4. Prior and posterior distributions of parameters ${ }^{33}$

\begin{tabular}{llllllll}
\hline \hline \multirow{2}{*}{ Parameter } & \multicolumn{3}{c}{ Prior Distribution } & \multicolumn{4}{c}{ Posterior Distribution } \\
\cline { 2 - 8 } & Distr. & Mean & SD & Mode & Mean & $5 \%$ & $95 \%$ \\
\hline$\eta$ & Normal & 2.5 & 0.25 & 3.5232 & 3.5426 & 3.2221 & 3.8428 \\
$h$ & Beta & 0.33 & 0.24 & 0.9172 & 0.9193 & 0.8892 & 0.9494 \\
\hline$\rho_{A}$ & Beta & 0.5 & 0.2 & 0.9434 & 0.9431 & 0.9285 & 0.9583 \\
$\rho_{\Omega_{c}}$ & Beta & 0.5 & 0.2 & 0.3863 & 0.3813 & 0.2564 & 0.5093 \\
$\rho_{\Omega_{n}}$ & Beta & 0.5 & 0.2 & 0.9693 & 0.9690 & 0.9555 & 0.9837 \\
$\rho_{\Omega_{G}}$ & Beta & 0.5 & 0.2 & 0.9021 & 0.8835 & 0.8283 & 0.9434 \\
\hline$\sigma_{A}$ & Inv-Gamma & 0.01 & Inf & 0.0193 & 0.0196 & 0.0159 & 0.0232 \\
$\sigma_{\Omega_{c}}$ & Inv-Gamma & 0.01 & Inf & 0.0500 & 0.0551 & 0.0336 & 0.0736 \\
$\sigma_{\Omega_{n}}$ & Inv-Gamma & 0.01 & Inf & 0.0056 & 0.0058 & 0.0046 & 0.0071 \\
$\sigma_{\Omega_{G}}$ & Inv-Gamma & 0.01 & Inf & 0.0143 & 0.0145 & 0.0117 & 0.0178 \\
$\sigma_{\varepsilon}^{m e}$ & Inv-Gamma & 0.01 & Inf & 0.0061 & 0.0061 & 0.0054 & 0.0067 \\
\hline
\end{tabular}

The third parameter set $\Theta_{3}^{U S}=\{\alpha, \theta\}$ contains the share parameter in the CES production function, $\alpha$, and the parameter of financial development, $\theta$. These two parameters are easy to pin down once we have information from $\Theta_{1}^{U S}$ and $\Theta_{2}^{U S} \cdot{ }^{34}$ In particular, given the calibration of $\Theta_{1}^{U S}$ and the estimation of $\Theta_{2}^{U S}$, the value of $\alpha$ is set such that the steady-state income share

\footnotetext{
${ }^{32}$ The priors on each parameter in $\Theta_{2}$ are summarized in Table 4 (left panel).

${ }^{33}$ To improve the match for consumption volatility, we included a habit-formation parameter $h=0.9$ in the parameter set $\Theta_{1}$ (in the spirit of Schmitt-Grohe and Uribe, 2012). This is an econometric trick that has little impact on the implications of our model.

${ }^{34}$ Technical speaking, the values of $\alpha$ and $\theta$ and the estimated values of $\Theta_{2}^{U S}$ are jointly determined, since the estimation of $\Theta_{2}^{U S}$ also depends on the values of $\alpha$ and $\theta$, see Del Negro and Schorfheide (2008) and Liu, Wang and Zha (2013) for the similar estimation strategy.
} 
of capital is 0.42 when $\theta \simeq 0$. According to Covas and Den Haan (2013)'s study on U.S. firm level financial conditions, we set the value of $\theta$ such that the model-implied average value of $\frac{\Delta \text { Debt }}{\Delta \text { Asset }}$ across firms in the steady state equals that in the U.S. data, which is $0.268 .{ }^{35}$

Table 4 presents the prior distributions of the parameters. It also presents the modes, means, and 5 th and 95 th percentiles of the posterior distributions for those parameters estimated using the Metropolis-Hastings algorithm with 200,000 draws. ${ }^{36}$ The values of $\Theta_{1}^{U S}$ and the posterior mode of $\Theta_{2}^{U S}$ imply that $\alpha=0.1794$ and $\theta=0.2688$. Under the estimated and calibrated parameter values, Table 5 reports the model-implied volatility (standard deviation of growth rate) for the four aggregate variables (where the estimated parameters are evaluated at posterior mode) and the counterparts in the U.S. data. It shows that the estimated model performs quite well in explaining the U.S. aggregate volatility in GDP, consumption, investment and hours.

Table 5. SD of growth rates for U.S.

\begin{tabular}{lcccc}
\hline \hline & $\Delta Y_{t}$ & $\Delta I_{t}$ & $\Delta C_{t}$ & $\Delta N_{t}$ \\
Data & 0.0083 & 0.0215 & 0.0045 & 0.0085 \\
Model & 0.0092 & 0.0220 & 0.0045 & 0.0090 \\
\hline
\end{tabular}

\subsection{Country-by-Country Estimation}

With the parameter values from the U.S. economy, we now apply Bayesian method to estimate our model for the other 31 OECD countries, using the U.S. economy as our benchmark. ${ }^{37}$ For these OECD countries, we partition the model parameters into two sets. The first set $\Theta_{1}^{O E C D}=\left\{\beta, \delta, \sigma, \gamma, h, \alpha, \frac{G}{Y}\right\}$ contains standard model parameters and is thus calibrated to the same values as those in the U.S. economy except for the government expenditures to GDP ratio $\frac{G}{Y}$, which is calibrated according to each country's average value over time. The second parameter set $\Theta_{2}^{O E C D}$ includes the remaining parameters, which are all to be estimated by the Bayesian method. This set includes the FD parameter $\theta$, the shape parameter for Pareto distribution $\eta$, and the parameters governing the shock processes $\left\{\rho_{\kappa}, \sigma_{\kappa}, \sigma_{\varepsilon}^{m e}\right\}$, where the index $\kappa=\left\{A, \Omega_{c}, \Omega_{n}, \Omega_{G}\right\}$. So, all parameters in $\Theta_{2}^{O E C D}$ are assumed to be country-specific and are estimated via Bayesian method. ${ }^{38}$ The prior distribution of $\theta$ follows Beta distribution and its

\footnotetext{
${ }^{35}$ Please also note that $\frac{\Delta \text { Debt }}{\Delta \text { Asset }}$ exactly corresponds to the variable $\frac{\Delta \frac{b_{t+1}(i)}{r_{t}}}{\Delta k_{t}(i)}$ in our model.

${ }^{36}$ The MCMC univariate convergence diagnostic (Brooks and Gelman (1998)) shows that our posterior distribution of each parameter constructed from random draws converges to a stationary distribution.

${ }^{37}$ We exclude Latovia and Switzerland due to the lack of data. We also exclude Iceland as an outlier since this country's investment is far more volatile than other OECD countries.

${ }^{38}$ Data Appendix V provides more detailed information about the data series used in the estimation.
} 
prior mean is set to 0.2688 (the U.S. value) adjusted (multiplied) by the corresponding country's own degree of FD relative to U.S. ${ }^{39}$ The prior standard deviation of $\theta$ is set to 0.05 . The prior distribution of the shape parameter $\eta$ follows normal distribution, with the prior mean equal to the U.S. value, and the prior standard deviation set to 0.2 . The priors of the parameters governing the shock processes are set in the same way as in the estimation procedure for the U.S. economy. Table 6 reports the posterior mode of the estimated parameters for each OECD country.

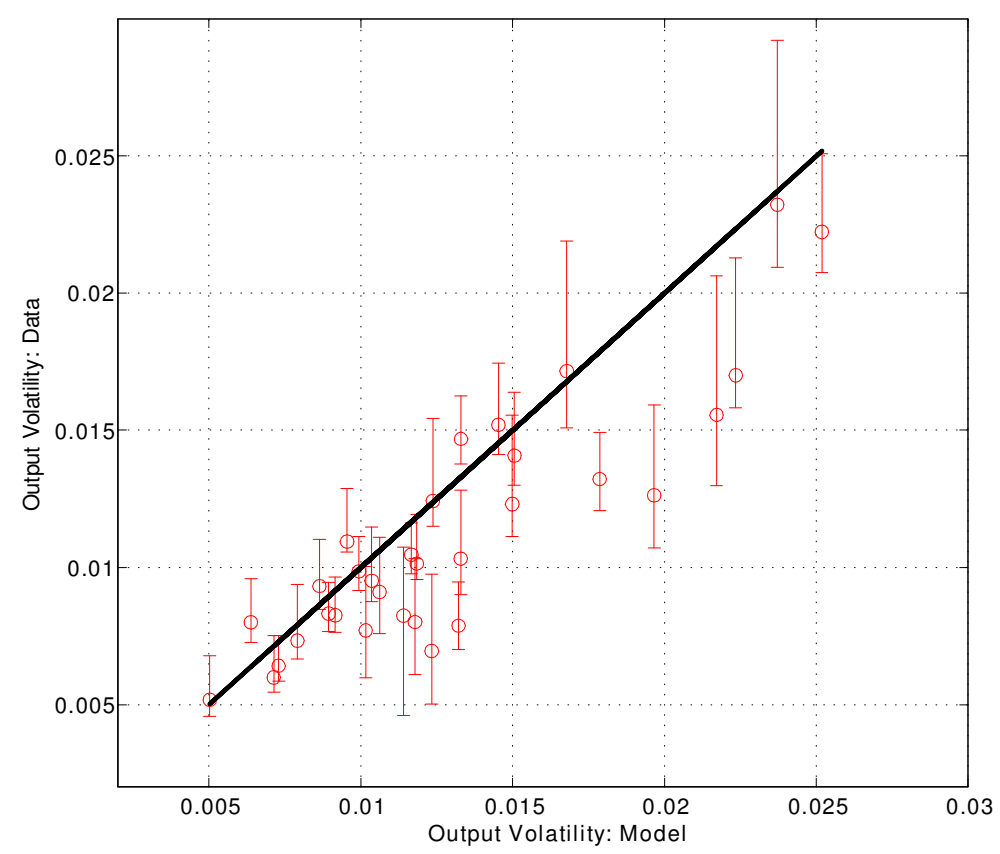

Figure 8. Output volatility: model v.s. data

To see the model's performance in terms of its goodness of fit, we compare the modelimplied GDP growth volatility (standard deviation) with that in the data in Figure 8, where the vertical axes indicates data, the horizontal axes indicates model, and a point on the 45 degree line indicates a perfect fit between model and data. ${ }^{40}$ The vertical bar around each circle indicates $95 \%$ quantile of the posterior simulations or the confidence interval. The figure shows that our model performs reasonably well in explaining the output volatility for most OECD countries (similarly for consumption, investment and hours).

\footnotetext{
${ }^{39}$ As a robustness analysis, we also use the U.S. value of $\theta$ as a common prior across all OECD countries without the adjustment (see Figure A1 in our online Appendix A). The results are robust.

${ }^{40}$ The model-implied output volatility is the theoretical standard deviation of output growth rate in the model. The vertical bar indicates $95 \%$ quantile based on 100,000 simulations under the posterior draws of estimated parameters. The output volatility for the data is the sample standard deviation of output growth over time.
} 
Table 6. Posterior mode for OECD countries

\begin{tabular}{|c|c|c|c|c|c|c|c|c|c|c|c|}
\hline Country & $\theta$ & $\eta$ & $\rho_{A}$ & $\rho_{\Omega_{c}}$ & $\rho_{\Omega_{n}}$ & $\rho_{\Omega_{G}}$ & $\sigma_{A}$ & $\sigma_{\Omega_{c}}$ & $\sigma_{\Omega_{g}}$ & $\sigma_{\Omega_{n}}$ & $\sigma_{\varepsilon}^{m e}$ \\
\hline U.S. & 0.2688 & 3.5232 & 0.9434 & 0.3863 & 0.9693 & 0.9021 & 0.0193 & 0.0500 & 0.0056 & 0.0143 & 0.0061 \\
\hline AUS & 0.0642 & 3.5905 & 0.9960 & 0.1568 & 0.8699 & 0.4183 & 0.0239 & 0.0960 & 0.0127 & 0.0283 & 0.0078 \\
\hline AUT & 0.1039 & 72 & 979 & 93 & 9298 & 83 & 0.0233 & 0.1651 & 0.0112 & 994 & 0.0046 \\
\hline BEL & 0.0473 & 3.7839 & 0.9775 & 0.3038 & 0.9174 & 0.1989 & 0.0132 & 0.0506 & 0.0059 & 0.0119 & 0.0061 \\
\hline CAN & 0.0744 & 3.8169 & 0.9788 & 1134 & 0.9508 & 0.4294 & 0.0172 & 0.0932 & 0.0062 & 0.0128 & 0.0075 \\
\hline CHL & 0.0180 & 3.5996 & 0.9873 & 0.3846 & 0.9227 & 0.4332 & 0.0275 & 0.1204 & 0.0128 & 0.0101 & 0.0127 \\
\hline $\mathrm{CZE}$ & 0.0800 & 3.5645 & 0.9725 & 526 & 0.8673 & 71 & 0.0164 & 912 & 0.0049 & 0.0205 & 0.0081 \\
\hline DEU & 0.1135 & 3.8298 & 0.9849 & 0.0454 & 0.9631 & 0.1763 & 0.0200 & 0.1201 & 0.0071 & 0.0225 & 0.0054 \\
\hline DNK & 0.1680 & 3.9125 & 0.9624 & 0.0768 & 0.9179 & 0.2172 & 0.0245 & 0.1402 & 0.0085 & 0.0280 & 0.0085 \\
\hline ESP & 0.1453 & 3.7653 & 0.9853 & 457 & 0.9474 & 79 & 0.0118 & 0.0846 & 091 & 0.0182 & 0.0043 \\
\hline EST & 0.0238 & 3.5792 & 0.9804 & 0.3129 & 0.6969 & 0.6719 & 0.0468 & 0.2063 & 0.0134 & 0.0087 & 0.0227 \\
\hline FIN & 0.0908 & 3.7515 & 0.9774 & 0.0544 & 0.9688 & 0.1448 & 0.0248 & 0.1679 & 0.0102 & 0.0259 & 0.0105 \\
\hline FRA & 0.1161 & 3.6073 & 0.9772 & 0.1267 & 0.8950 & 0.5048 & 0.0110 & 0.0525 & 0.0043 & 0.0042 & 0.0027 \\
\hline GBR & 0.1347 & 3.7371 & 0.9775 & 0.1230 & 645 & 65 & 0.0278 & 0.0763 & 0.0038 & 0.0058 & 0.0104 \\
\hline GRC & 0.0433 & 3.7002 & 0.9666 & 0.1530 & 0.9593 & 0.4941 & 0.0409 & 0.1870 & 0.0125 & 0.0123 & 0.0143 \\
\hline HUN & 0.1878 & 3.5349 & 0.9908 & 0.0681 & 0.8812 & 0.7855 & 0.0282 & 0.1506 & 0.0052 & 0.0088 & 0.0095 \\
\hline IRL & 0.0 & 057 & 05 & 864 & 0.9405 & 0.8 & 0.0279 & 0.1567 & 0.0068 & 0.0338 & 0.0139 \\
\hline ISR & 0.0834 & 3.6442 & 0.9839 & 0.1459 & 0.9382 & 0.2174 & 0.0179 & 0.1426 & 0.0108 & 0.0268 & 0.0081 \\
\hline ITA & 0.1 & 3.6 & 0. & 0. & 0. & 0 . & 59 & 40 & 42 & 64 & 0.0054 \\
\hline JPN & 0.3684 & 3.9568 & 0.9919 & 0.0568 & 0.9535 & 0.6488 & 0.0235 & 0.1466 & 0.0079 & 0.0322 & 0.0050 \\
\hline KOR & 0.1585 & 3.6322 & 0.9876 & 923 & 424 & 673 & 320 & 05 & 51 & 542 & 0.0109 \\
\hline LUX & 0.0602 & 3.9227 & 0.9834 & 0.1876 & 0.9450 & 0.4636 & 0.0389 & 0.1222 & 0.0213 & 0.0640 & 0.0192 \\
\hline MEX & 0.0048 & 3.6387 & 0.9871 & 573 & 0.9524 & 288 & 0.0192 & 338 & 0.0163 & 0.0919 & 0.0070 \\
\hline NLD & 0.1394 & 3.7801 & 0.9741 & 0.1160 & 0.9278 & 0.4635 & 0.0219 & 0.0748 & 0.0052 & 0.0081 & 0.0071 \\
\hline NOR & 0.0757 & 3.5926 & 0.9544 & 0.0867 & 0.2696 & 0.2481 & 0.0237 & 0.1378 & 0.0146 & 0.0730 & 0.0140 \\
\hline NZL & 0.0665 & 3.9599 & 0.9640 & 0.0759 & 0.8711 & 0.5600 & 0.0150 & 0.1278 & 0.0110 & 0.0622 & 0.0046 \\
\hline POL & 0.0165 & 3.6242 & 0.9663 & 0.2039 & 0.8693 & 0.5841 & 0.0130 & 0.0652 & 0.0060 & 0.0128 & 0.0076 \\
\hline PRT & 0.1225 & 3.7507 & 0.9763 & 0.2331 & 0.9238 & 0.5798 & 0.0246 & 0.1039 & 0.0046 & 0.0121 & 0.0088 \\
\hline SVK & 0.0205 & 3.5587 & 0.9597 & 0.2550 & 0.9115 & 0.5818 & 0.0320 & 0.0886 & 0.0064 & 0.0152 & 0.0194 \\
\hline SVN & 0.0363 & 3.5797 & 0.9597 & 0.1192 & 0.8803 & 0.4199 & 0.0203 & 0.1210 & 0.0093 & 0.0290 & 0.0073 \\
\hline SWE & 0.2815 & 2.6293 & 0.9820 & 0.2114 & 0.9408 & 0.8701 & 0.0639 & 0.1155 & 0.0404 & 0.0555 & 0.0056 \\
\hline TUR & 0.0355 & 3.8359 & 0.9897 & 0.0687 & 0.8400 & 0.7182 & 0.0443 & 0.3012 & 0.0130 & 0.0896 & 0.0104 \\
\hline
\end{tabular}




\subsection{Financial Development and Volatility}

With the estimated parameters for each country, we can ask two questions: (i) Is there a negative relationship between the estimated value of $\theta$ and GDP volatility in the data? (ii) How does the volatility of GDP in a country change when the estimated parameter $\theta$ in that country is replaced by the U.S. value while keeping everything else the same?

The answers to these questions are not so obvious, because countries with lower aggregate volatility could be driven by smaller aggregate shocks instead of better FD (higher value of $\theta$ ). This implies that our estimates (after controlling for shocks) may show that countries with lower volatility tend to have worse FD.

To answer question (i), Figure 9 presents scatter plots for the relationship between the estimated degree of FD $(\theta)$ and the observed aggregate GDP volatility for each OECD country. ${ }^{41}$ It shows a general L-shaped relationship, consistent with the stylized facts presented previously; namely, a country with a higher value of $\theta$ tends to have a lower output volatility. The correlation between the estimated $\theta$ and output volatility is significantly negative at -0.34 .

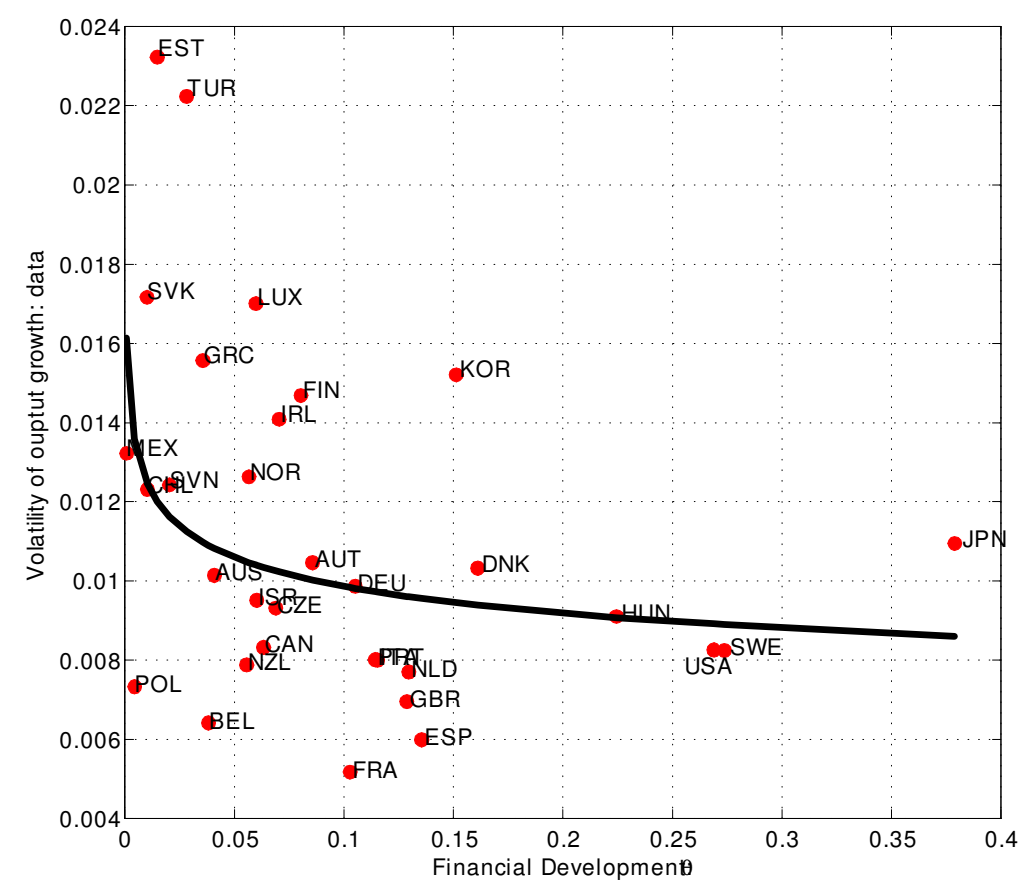

Figure 9. Financial development (model) and output volatility (data).

Note: Output volatility is the standard deviation of output growth in the data; financial development is measured by the estimated posterior mode of $\theta$.

\footnotetext{
${ }^{41}$ The results are similar if we plot the estimated FD against model-implied output volatility.
} 
To answer question (ii), we document the impact of financial development on aggregate volatility through the following counterfactual exercise. Namely, for each OECD country we replace its estimated financial development parameter $\theta$ by the U.S. value, and compute the changes in the model-implied output volatility. Table 7 summarizes the main results. The column under " $\Delta \mathrm{Vol} "$ shows that when a country's financial system achieves the U.S. level (which is presumably more advanced than most OECD countries), its volatility of aggregate output growth reduces significantly. ${ }^{42}$

Table 7. Financial development and output volatility

\begin{tabular}{lccccccc}
\hline \hline \multicolumn{7}{c}{ Standard Deviation of $\Delta Y_{t}$} \\
\hline & Bench & US $\theta$ & $\Delta$ Vol & & Bench & US $\theta$ & $\Delta$ Vol \\
\hline AUS & 0.0118 & 0.0098 & $-16.84 \%$ & ISR & 0.0104 & 0.0086 & $-17.38 \%$ \\
AUT & 0.0117 & 0.0101 & $-13.23 \%$ & ITA & 0.0064 & 0.0058 & $-8.87 \%$ \\
BEL & 0.0073 & 0.0062 & $-14.67 \%$ & JPN & 0.0095 & 0.0100 & $4.59 \%$ \\
CAN & 0.0089 & 0.0079 & $-11.97 \%$ & KOR & 0.0145 & 0.0135 & $-7.03 \%$ \\
CHL & 0.0150 & 0.0121 & $-19.27 \%$ & LUX & 0.0223 & 0.0197 & $-11.85 \%$ \\
CZE & 0.0086 & 0.0073 & $-15.27 \%$ & MEX & 0.0179 & 0.0124 & $-30.61 \%$ \\
DEU & 0.0099 & 0.0090 & $-9.32 \%$ & NLD & 0.0102 & 0.0095 & $-6.65 \%$ \\
DNK & 0.0133 & 0.0125 & $-5.79 \%$ & NOR & 0.0197 & 0.0156 & $-20.79 \%$ \\
ESP & 0.0071 & 0.0065 & $-8.76 \%$ & NZL & 0.0132 & 0.0109 & $-17.20 \%$ \\
EST & 0.0237 & 0.0191 & $-19.46 \%$ & POL & 0.0079 & 0.0062 & $-21.58 \%$ \\
FIN & 0.0133 & 0.0116 & $-12.40 \%$ & PRT & 0.0118 & 0.0108 & $-8.00 \%$ \\
FRA & 0.0050 & 0.0045 & $-10.37 \%$ & SVK & 0.0168 & 0.0136 & $-18.77 \%$ \\
GBR & 0.0123 & 0.0115 & $-6.83 \%$ & SVN & 0.0124 & 0.0096 & $-22.33 \%$ \\
GRC & 0.0217 & 0.0185 & $-14.83 \%$ & SWE & 0.0114 & 0.0117 & $2.39 \%$ \\
HUN & 0.0106 & 0.0103 & $-3.03 \%$ & TUR & 0.0252 & 0.0207 & $-17.91 \%$ \\
IRL & 0.0151 & 0.0130 & $-13.73 \%$ & & & & \\
\hline
\end{tabular}

Note: The "Bench" column refers to the estimated value (posterior mode); the "US $\theta$ " column refers to the value based on simulations with $\theta$ evaluated at 0.2688 (the U.S. value) while keeping other parameter values fixed. The " $\Delta \mathrm{Vol} "$ column computes the percentage changes in output volatility between "Bench" and "US $\theta$ ".

\footnotetext{
${ }^{42}$ The exceptions are Japan and Sweden. In our estimation, the parameter $\theta$ in Japan and Sweden is larger than that in U.S. As a result, setting these countries' $\theta$ to the U.S. value raises their output volatility.
} 


\subsection{Other Robustness Analyses}

We have also conducted a series of other robustness analyses to test the implications of our model. For example, a potential problem of our analysis is that output volatility is a single statistics while financial development measured by total credit supply is a time series that may have time trend. Although we are unable to solve such problems, here we partially address this issue by panel regression based on subsamples with both country-specific and time fixed effects. We split the total sample evenly into two subsamples: 1989-1997 and 1998-2006. This would allow us to mitigate the time trend effects presented in our measures of financial development. Note that we do not adopt the conventional 5-year average simply because 5-year span is not long enough to compute the standard deviation of macro variables over time. Our panel regression follows Kose, Prasad and Terrones (2003). In particular, the dependent variable is the standard deviation of output growth in each subsample. The independent variables include: the average financial development and its quadratic term with a power of -2 (to capture the possible L-shape), the financial openness (defined as the average capital flows to GDP ratio) and its square term, the relative income, the M2/GDP and its standard deviation, the average inflation rate, and the standard deviation of fiscal expenditure (as \% share of GDP). Note that all the level variables are the average value in each subsample. The table below reports the results for both OLS and FE estimation. The table shows that after controlling the countryspecific fixed effect and (partially) the time trend effects, the L-shaped relationship between output volatility and financial development remains robust.

There is also a large literature on business cycles in emerging economies (e.g. Aguiar and Gopinath 2007; Neumeyer and Perri, 2005; among others). This literature documents high volatilities in consumption, output and investment in emerging economies (relative to developed countries), as well as the fact that consumption is more volatile than output in developing countries, which are all in line with our model's predictions. These studies also document that the correlation of aggregate investment with GDP over the cycle is stronger in emerging economies than in developed countries. This stylized fact is also the prediction of our model. To conserve space, the analyses and results are summarized in Appendix V (Online Appendix A) and Appendix VI (Online Appendix B), which also include other types of robustness analyses. 
Table 8. Panel non-linear regression

\begin{tabular}{lcc}
\hline \hline & OLS & $\mathrm{FE}$ \\
$\mathrm{FD}^{-2}$ & $0.393^{* * *}$ & $1.897^{* * *}$ \\
& $(0.085)$ & $(0.716)$ \\
$\mathrm{FD}$ & -0.000 & $-0.001^{* * *}$ \\
& $(0.000)$ & $(0.000)$ \\
trade openness & $0.008^{* *}$ & $-0.117^{* * *}$ \\
& $(0.004)$ & $(0.038)$ \\
capital flows & -0.001 & $0.084^{* * *}$ \\
& $(0.001)$ & $(0.027)$ \\
capital flows square & 0.000 & $-0.007^{*}$ \\
& $(0.000)$ & $(0.004)$ \\
relative income & -0.002 & 0.213 \\
& $(0.002)$ & $(0.450)$ \\
s.d. terms of trade & 0.001 & $0.001^{* *}$ \\
& $(0.000)$ & $(0.000)$ \\
M2/GDP & -0.000 & $0.001^{* *}$ \\
& $(0.000)$ & $(0.001)$ \\
s.d. M2/GDP & -0.000 & $0.003^{* *}$ \\
& $(0.000)$ & $(0.001)$ \\
average inflation & $0.000^{* * *}$ & -0.000 \\
fiscal policy volatility & $(0.000)$ & $(0.000)$ \\
R & 0.108 & 0.195 \\
\# of observation & $(0.190)$ & $(0.548)$ \\
\hline
\end{tabular}

\section{Conclusion}

Financial development is one of the most important economic and institutional changes in modern human history and the postwar industrial world. It has had many far-reaching consequences that economists have only recently begun to appreciate, such as the ever-increasing consumption-to-GDP ratio and declining household savings rate (Bayoumi, 1993), the increased ability to generate financial assets to attract world savings and the consequent global financial imbalances (Caballero, Farhi, and Gourinchas, 2008), and the sustained economic growth despite a relatively low aggregate investment rate (King and Levine, 1993; Greenwood, Sanchez, 
and Wang, 2007). ${ }^{43}$

This paper adds to the above list yet another set of possible consequences of financial development, including (i) a decreasing trend in aggregate volatility and (ii) an increasing dispersion of firm level activities (for publicly traded firms). Indeed, the existing empirical studies and our work show that (i) across countries, better FD is associated with a lower aggregate volatility but this volatility-reduction effect diminishes with further FD; and (ii) over time, improved financial conditions are associated with increased dispersions in firms' sales growth and stock returns.

We offer a simple theoretical model to rationalize these diverging trends in aggregate and firm-level volatilities as well as the non-linearity inherited in the downward aggregate volatility trends. The explanation is based on the understanding (Levine, 2005) that FD relaxes borrowing constraints and promotes better credit allocation among firms. Our dynamic stochastic general equilibrium model predicts that (i) FD or financial liberalization increases firm-level volatility by allowing more productive firms to expand their capital stocks through borrowing external funds and letting less productive firms reduce losses through savings in the financial market; and (ii) at the same time, FD reduces aggregate volatility by making firms' investment decisions less dependent on internal cash flows and more dependent on external funding. Hence, aggregate shocks that primarily affect firms' cash flows will have less impact on aggregate investment and output.

Our model may also shed light on several important issues that have not been well researched. First, the increasing dispersion of economic activities over time is observed not only in firms but also in households. The recent empirical literature on household income dynamics has found a gradual increase in the volatility and inequality in household income and consumption (see, e.g., Krueger and Perri, 2006; Heathcote, Storesletten, and Violante, 2007; Gorbachev, 2010). Since the main sources of household income are wage earnings and returns to financial wealth, the rising dispersion and inequality in household income may also be closely related to FD. If this conjecture is correct, our model also offers an explanation for the rising dispersion and volatility trend at the household level. This conjecture, however, is left for future research.

Second, following a series of financial liberalizations and banking-policy changes in the U.S. since the 1980s, the nation entered a period of great moderation until the recent 2008 financial crisis. Our model implies that the great moderation and financial liberalization may be closely related. However, the recent financial crisis increased aggregate volatility for the great moderation period and pushed the U.S. into a deep recession, as if the great moderation has ended. Many economists attribute the deep recession to financial shocks (e.g., see Jermman

\footnotetext{
${ }^{43}$ The recent financial crisis may also be related to rapid financial development and financial innovations, a point we will return to later.
} 
and Quadrini, 2011). This view is not inconsistent with our theory. In our model, FD implies that firms rely more heavily on external finance. As a result, shocks to external finance (such as to the parameter $\theta$ in our model) would have a larger impact on aggregate volatility in a more financially developed country (such as the U.S.) than in a less financially developed country (such as China). Our impulse response analysis confirms this prediction. ${ }^{44}$

Nonetheless, our model can capture some empirical facts but not others. For example, the issue of the differences between private and publicly traded companies cannot be properly addressed in the current model. According to Haltiwanger, Davis, Jarmin and Miranda (2006), private companies has become less volatile in the US. Our theory seems consistent with publicly traded companies (greater idiosyncratic volatility associated with lower aggregate volatility), but not with privately traded firms. Essentially, our model features an ex-ante representative firm (firms are heterogeneous ex-post but the heterogeneity lasts for only one period). Therefore, it cannot capture ex-ante heterogeneity observed in the data because the model is not designed to capture heterogeneity that are based on ex-ante differences among firms. Without explicit modeling of private versus public companies, the model cannot capture differences between private and public companies. We leave such issues for future research.

\footnotetext{
${ }^{44}$ Also see Figure 5 about the impact of the Asian financial crisis. To conserve space, the impulse response analysis under financial shocks to $\theta$ is not reported here but is available upon request. Our theory suggests that the dynamics of lumpy investment that we see in different countries may be affected by financial development. This implication could be analyzed in future work.
} 


\section{References}

[1] Aghion, P., G. Angeletos, A. Banerjee, and K. Manova, 2010, Volatility and growth: Credit constraints and the composition of investment, Journal of Monetary Economics 57(3), 246265 .

[2] Aguiar, Mark, and Gita Gopinath. "Emerging Market Business Cycles: The Cycle Is the Trend." Journal of Political Economy 115.1, 2007, 69-102.

[3] Bai, Y., V. Rios-Rull, and K. Storesletten, 2011, Demand Shocks that Look Like Productivity Shocks, Working Paper.

[4] Bayoumi, T., 1993, Financial deregulation and household saving, The Economic Journal $103,1432-1443$.

[5] Beck, T., A. Demirgüç-Kunt, and R. Levine, 2010, Financial institutions and markets across countries and over time: The updated financial development and structure database, The World Bank Economic Review 24(1), 77-92.

[6] Bekaert, G., C. Harvey, and C. Lundblad, 2004, Growth Volatility and Financial Liberalization, Working Paper.

[7] Bernanke, B., M. Gertler and S. Gilchrist, 1999, The financial accelerator in a quantitative business cycle framework, Handbook of Macroeconomics, Vol 1, Part C, 1341-1393.

[8] Blanchard, O., 1989. A traditional interpretation of macroeconomic fluctuations. The American Economic Review, pp.1146-1164.

[9] Blanchard, O. and J. Simon, 2001, The long and large decline in U.S. output volatility, Brookings Paper on Economic Activity, 1, 135-164.

[10] Braun, Matias, and Borja Larrain. "Finance and the business cycle: international, interindustry evidence." The Journal of Finance 60.3 (2005): 1097-1128.

[11] Brooks, S.P. and Gelman, A., 1998. General methods for monitoring convergence of iterative simulations. Journal of computational and graphical statistics, 7(4), pp.434-455.

[12] Caballero, Ricardo, Emmanuel Farhi, and Pierre-Olivier Gourinchas, 2008, An equilibrium model of global imbalances and low interest rates, American Economic Review 98(1), 358393. 
[13] Campbell J. and Z. Hercowitz, 2006, The role of collateralized household debt in macroeconomic stabilization, mimeo, Federal Reserve Bank of Chicago.

[14] Campbell, J., M. Lettau, B.Malkiel, and Y. Xu, 2001, Have individual stocks become more volatile? An Empirical Exploration of Idiosyncratic Risk," Journal of Finance, 56(1), 1-43.

[15] Caplin, A. and J. Leahy, 2006, Equilibrium in a durable goods market with lumpy adjustment, Journal of Economic Theory, 128 (1), 187-213.

[16] Chaney, T., X. Gabaix, and T. Philippon, 2002, Firm volatility, Mimeo, MIT.

[17] Christiano, L. and M. Eichenbaum, 1992, Current Real-Business-Cycle Theories and Aggregate Labor-Market Fluctuations, The American Economic Review 82(3), 432-450.

[18] Christiano, L., M. Eichenbaum, C. Evans, 2005, Nominal Rigidities and the Dynamic Effects of a Shock to Monetary Policy, Journal of Political Economy 113(1), 1-45.

[19] Comin, D., 2000, "An uncertainty-Driven Theory of the Productivity Slowdown: Manufacturing," C.V. Starrr working paper no. 200-216.

[20] Comin, D. and S. Mulani, 2006, Diverging Trends in Aggregate and Firm-level Volatility, The Review of Economics and Statistics 88(2), 374-383.

[21] Comin, D. and S. Mulani, 2009, A Theory of Growth and Volatility at the Aggregate and Firm Level, Journal of Monetary Economics 56(8), 1023-1042.

[22] Comin, D. and T. Philippon, 2005, The Rise in Firm-Level Volatility: Causes and Consequences, NBER Macroeconomics Annual 20, 167-228.

[23] Cooley, T. and V. Quadrini, 2001, Financial markets and firm dynamics, American Economic Review 91(5), 1286-1310.

[24] Cooper, R. and J. Haltiwanger, 2006, On the nature of capital adjustment costs, Review of Economic Studies 73, 611-633.

[25] Dellasa, H. and M. Hessb, 2005, Financial development and stock returns: A cross-country analysis, Journal of International Money and Finance 24(6), 891-912.

[26] Davis, S, J. Haltiwanger, R. Jarmin, and J. Miranda, 2006, Volatility and Dispersion in Business Growth Rates: Publicly Traded versus Privately Held Firms, NBER Working Paper 12354. 
[27] Del Negro, M. and Schorfheide, F., 2008. Forming priors for DSGE models (and how it affects the assessment of nominal rigidities). Journal of Monetary Economics, 55(7), pp.1191-1208.

[28] Dynan, K., D. Elmendorf, and D. Sichel, 2006a, Can Financial Innovation Help to Explain the Reduced Volatility of Economic Activity? Journal of Monetary Economics, 123-150.

[29] Dynan, K., D. Elmendorf, and D. Sichel, 2006b, Financial Innovation and the Great Moderation: What Do Household Data Say? Working Paper, Federal Reserve Board.

[30] Duffy J. and C. Papageorgiou, 2000; A Cross-Country Empirical Investigation of the Aggregate Production Function Specification, Journal of Economic Growth 5, 87-20.

[31] Easterly, W., R. Islam, and J. Stiglitz, 2000, Explaining Growth Volatility, Working Paper, The World Bank.

[32] Eichenbaum, M., 1991, Real business-cycle theory: Wisdom or whimsy, Journal of Economic Dynamics and Control 15(4), 607-626.

[33] Fazzari, S., R. Hubbard, and B. Petersen, 1988, Financing Constraints and Corporate Investment, Brookings Papers on Economic Activity 1988 (1), 141-206.

[34] Franco, F. and T. Philippon, 2004, Firms and aggregate dynamics, mimeo NYU.

[35] Galí, J. and Rabanal, P., 2004. Technology Shocks and Aggregate Fluctuations: How Well Does the Real Business Cycle Model Fit Postwar US Data?. NBER macroeconomics annual, 19, pp.225-288.

[36] Goldsmith, R.W., 1969, Financial Structure and Development. Yale University Press, New Haven, CT.

[37] Greenwood, J., Hercowitz, and Krusell, 1997, Long-run implications of investment-specific technological change, American Economic Review

[38] Greenwood, J., J. Sanchez, and C. Wang, 2007, Financial development: The role of information costs, NBER Working Paper 13104.

[39] Guvenen, F., and T. Philippon, 2005, Firm volatility and wage inequality, mimeo.

[40] Jermann, U. and V. Quadrini, 2009, "Financial Innovations and Macroeconomic Volatility," NBER Working Paper 12308. 
[41] Jermann, U. and V. Quadrini, 2012. Macroeconomic effects of financial shocks. The American Economic Review, 102(1), pp.238-271.

[42] Kaminsky, Graciela and Sergio Schmukler, "Short-Run Pain, Long-Run Gain: Financial Liberalization and Stock Market Cycles" Review of Finance, Vol. 12, 2008, 253-292.

[43] King, R.G. and Levine, R., 1993. Finance and growth: Schumpeter might be right. The Quarterly Journal of Economics, 108(3), pp.717-737.

[44] Kiyotaki, N. and J. Moore, 1997, Credit cycles, Journal of Political Economy 105(2), 211247.

[45] Krusell, P. and A. Smith, Jr., 1998, Income and wealth heterogeneity in the macroeconomy, Journal of Political Economy, 106(5), 867-896.

[46] Levine, R., 2005, Finance and growth: Theory and evidence, in Handbook of Economic Growth, Volume 1A. Edited by Philippe Aghion and Steven N. Durlauf, Elsevier B.V.

[47] Liu, Z., Wang, P. and Zha, T., 2013. Land-price dynamics and macroeconomic fluctuations. Econometrica, 81(3), pp.1147-1184.

[48] Mankiw, N.G., 1989. Real Business Cycles: A New Keynesian Perspective. The Journal of Economic Perspectives, 3(3), pp.79-90.

[49] Masanjala W. and C. Papageorgiou, 2004, The Solow model with CES technology: Nonlinearities and parameter heterogeneity, Journal of Applied Econometrics 19, 171-201.

[50] McKinnon, R.I., 1973, Money and Capital in Economic Development, Brookings Institution, Washington, DC.

[51] Neumeyer, Pablo A., and Fabrizio Perri. "Business cycles in emerging economies: the role of interest rates." Journal of monetary Economics 52.2 (2005): 345-380.

[52] Parker, M., 2006, Diverging Trends in Aggregate and Firm-Level Volatility in the UK, External MPC Unit Discussion Paper No. 16, Bank of England.

[53] Peralta-Alva, A. and M. Santos, 2010, Problems in the Numerical Simulation of Models with Heterogeneous Agents and Economic Distortions, Journal of the European Economic Association 8(2-3), 617-25. 
[54] Pintus, P. and Y. Wen, 2010, Leveraged borrowing and boom-bust cycles, Federal Reserve Bank of St. Louis Working Paper 2010-027A.

[55] Raddatz, Claudio. "Liquidity needs and vulnerability to financial underdevelopment." Journal of financial economics 80.3 (2006): 677-722.

[56] Schumpeter, J.A., 1912, Theorie der wirtschaftlichen Entwicklung. Dunker \& Humblot, Leipzig. The Theory of Economic Development translated by R. Opie. Harvard University Press, Cambridge, MA, 1934.

[57] Summers, L.H., 1986. Does the stock market rationally reflect fundamental values?. The Journal of Finance, 41(3), pp.591-601.

[58] Wang, P.F and Y. Wen, 2009, Financial Development and Economic Volatility: A Unified Explanation, Federal Reserve Bank of St. Louis Working Paper 2009-022C.

[59] Wang, P.F and Y. Wen, 2011, Volatility, growth, and welfare, Journal of Economic Dynamics and Control 35(10), 1696-1709.

[60] Wang, P.F and Y. Wen, 2012, Hayashi Meets Kiyotaki And Moore: A Theory Of Capital Adjustment Costs, Review of Economic Dynamics, 15(2), 207-225.

[61] Wang, P.F and Y. Wen, 2012, Speculative bubbles and financial crises, American Economic Journal: Macroeconomics 4(3), 1-40. 


\section{Appendix I.A. Proof of Proposition 1}

Proof. Consider two possible cases for the size of the efficiency shock $\varepsilon_{t}(i)$.

Case A: $\varepsilon_{t}(i) \geq \varepsilon_{t}^{*}$. In this case, firm $i$ receives a favorable shock. Suppose this induces the firm to invest, we then have $i_{t}(i)>0$ and $\pi_{t}(i)=0$. By the law of iterated expectations, equations (23) and (24) then become

$$
\frac{1+\mu_{t}(i)}{\varepsilon_{t}(i)}=\beta E_{t} \frac{\Lambda_{t+1}}{\Lambda_{t}}\left\{\left[1+\bar{\mu}_{t+1}\right] R_{t+1}+(1-\delta) \bar{\lambda}_{t+1}+\theta \bar{\phi}_{t+1}\right\}
$$

Since the multiplier $\mu_{t}(i) \geq 0$, this equation implies

$$
\varepsilon_{t}(i) \geq\left[\beta E_{t} \frac{\Lambda_{t+1}}{\Lambda_{t}}\left\{\left[1+\bar{\mu}_{t+1}\right] R_{t+1}+(1-\delta) \bar{\lambda}_{t+1}+\theta \bar{\phi}_{t+1}\right\}\right]^{-1} \equiv \varepsilon_{t}^{*}
$$

Since $\pi(i)=0$, equations $(23)$ and $(24)$ then become

$$
\frac{1+\mu_{t}(i)}{\varepsilon_{t}(i)}=\frac{1}{\varepsilon_{t}^{*}}
$$

Hence, $\mu_{t}(i)>0$ if and only if $\varepsilon_{t}(i)>\varepsilon_{t}^{*}$. It follows that under Case A firm $i$ opts to invest at full capacity,

$$
i_{t}(i)=R_{t} k_{t}(i)+\frac{b_{t+1}(i)}{r_{t}}-b_{t}(i)
$$

and pays no dividend. Also, since $\mu_{t}(i) \geq 0$, equation (25) implies

$$
\phi_{t}(i) \geq \frac{1}{r_{t}}-\beta E_{t} \frac{\Lambda_{t+1}}{\Lambda_{t}}\left\{\left[1+\bar{\mu}_{t+1}\right]\right\} \equiv \phi_{t}^{*}
$$

where the right-hand side defines the cutoff $\phi_{t}^{*}$, which is independent of $i$. Note that $\phi_{t}^{*} \geq 0$ because it is the value of the Lagrangian multiplier when $\mu_{t}(i)=0$. Hence, equation (25) can also be written as

$$
\phi_{t}(i)=\frac{\varepsilon_{t}(i)-\varepsilon_{t}^{*}}{\varepsilon_{t}^{*}} \frac{1}{r_{t}}+\phi_{t}^{*}
$$

Because $\phi_{t}^{*} \geq 0$, we have $\phi_{t}(i)>0$ when $\varepsilon_{t}(i)>\varepsilon_{t}^{*}$, which means that under Case A firms are willing to borrow up to the borrowing limit $b_{t+1}(i)=\theta k_{t}(i)$ to finance investment. Therefore, 
the optimal investment equation (57) can be rewritten as

$$
i_{t}(i)=\left[R_{t}+\frac{\theta}{r_{t}}\right] k_{t}(i)-b_{t}(i)
$$

To ensure $i_{t}(i)>0$ at steady state, we restrict the parameter values such that the condition $\left(R+\frac{\theta}{r}\right)(1-\delta)>\theta$ is always satisfied.

Case B: $\varepsilon_{t}(i)<\varepsilon_{t}^{*}$. In this case, firm $i$ receives an unfavorable shock. Assume that the firm decides to underinvest, $i_{t}(i)<R_{t} k_{t}(i)+\frac{b_{t+1}}{r_{t}}-b_{t}$, then the multiplier $\mu_{t}(i)=0$. Equation $(23)$ implies $\pi_{t}(i)=\frac{1}{\varepsilon_{t}(i)}-\frac{1}{\varepsilon_{t}^{*}}>0$. Thus, confirming our assumption, the firm opts not to invest and $i_{t}(i)=0$. Since $\int_{0}^{1} b_{t+1}(i) d i=0$, and $b_{t+1}(i)=\theta k_{t}(i)>0$ when $\varepsilon_{t}(i)>\varepsilon_{t}^{*}(i)$, there must exist firms indexed by $j$ such that $b_{t+1}(j)<0$ if $\varepsilon_{t}(j)<\varepsilon_{t}^{*}$. It then follows that $\phi_{t}(i)=\phi_{t}^{*}=0$ under Case B. That is, firms receiving unfavorable shocks will not invest in fixed capital but will instead opt to invest in financial assets in the bond market by lending a portion of their cash flows to other (more productive) firms.

A firm's optimal investment strategy is thus given by the decision rule in equation (26), and the Lagrangian multipliers satisfy:

$$
\begin{gathered}
\pi_{t}(i)=\left\{\begin{array}{cc}
0 & \text { if } \varepsilon_{t}(i) \geq \varepsilon_{t}^{*} \\
\frac{1}{\varepsilon(i)}-\frac{1}{\varepsilon^{*}} & \text { if } \varepsilon_{t}(i)<\varepsilon_{t}^{*}
\end{array},\right. \\
\mu_{t}(i)=\left\{\begin{array}{cc}
\frac{\varepsilon_{t}(i)-\varepsilon_{t}^{*}}{\varepsilon_{t}^{*}} & \text { if } \varepsilon_{t}(i) \geq \varepsilon_{t}^{*} \\
0 & \text { if } \varepsilon_{t}(i)<\varepsilon_{t}^{*}
\end{array}\right. \\
\phi_{t}(i)=\left\{\begin{array}{cc}
\frac{\varepsilon_{t}(i)-\varepsilon_{t}^{*}}{\varepsilon_{t}^{*}} \frac{1}{r_{t}} & \text { if } \varepsilon_{t}(i) \geq \varepsilon_{t}^{*} \\
0 & \text { if } \varepsilon_{t}(i)<\varepsilon_{t}^{*}
\end{array}\right.
\end{gathered}
$$

Using equations (61) to (63), we can write the cutoff $\varepsilon_{t}^{*}$ recursively as in equation (27). Finally, by the relationship $\lambda_{t}(i)=\frac{1}{\varepsilon_{t}^{*}}$ and equations (61) to (63), it is clear that all the Lagrangian multipliers $\left\{\lambda_{t}(i), \pi_{t}(i), \mu_{t}(i), \phi_{t}(i)\right\}$ depend only on aggregate states and the current idiosyncratic shock $\varepsilon_{t}(i)$. Hence, their expected values $\left\{\bar{\lambda}_{t}, \bar{\pi}_{t}, \bar{\mu}_{t}, \bar{\phi}_{t}\right\}$ are independent of $i$. 


\section{Appendix I.B. Proof of Corollary 1}

Proof. Using equation (62), we can rewrite equation (25) as

$$
\frac{\left[1+\mu_{t}(i)\right]}{r_{t}}=\beta E_{t} \frac{\Lambda_{t+1}}{\Lambda_{t}} Q\left(\varepsilon_{t+1}^{*}\right)+\phi_{t}(i)
$$

Evaluating this equation for firms with $\varepsilon_{t}(i)<\varepsilon_{t}^{*}$ yields equation $(29)$.

\section{Appendix II. Proof of Proposition 2}

Proof. By definition, the aggregate investment $I_{t} \equiv \int i_{t}(i) d i$. Integrating equation (26) gives

$$
I_{t}=\left[R_{t}+\frac{\theta}{r_{t}}\right] \int_{\varepsilon_{t}(i) \geq \varepsilon_{t}^{*}}\left[k_{t}(i)-b_{t}(i)\right] d i .
$$

Because $\int b_{t}(i) d i=0$ and $\varepsilon_{t}(i)$ is independent of the predetermined variables $\left\{b_{t}(i), k_{t}(i)\right\}$ and any aggregate shocks, by the law of large numbers the aggregate investment becomes

$$
I_{t}=\left(R_{t}+\frac{\theta}{r_{t}}\right) K_{t}\left[1-F\left(\varepsilon_{t}^{*}\right)\right]
$$

The aggregate capital stock evolves according to

$$
K_{t+1}=(1-\delta) K_{t}+\int_{\varepsilon_{t}(i) \geq \varepsilon_{t}^{*}} i_{t}(i) \varepsilon_{t}(i) d i
$$

which by the firm-level investment decision rule implies

$$
\begin{aligned}
K_{t+1} & =(1-\delta) K_{t}+\left[R_{t}+\frac{\theta}{r_{t}}\right] K_{t} \int_{\varepsilon_{t}(i) \geq \varepsilon_{t}^{*}} \varepsilon_{t}(i) d i \\
& =(1-\delta) K_{t}+I_{t}\left[1-F\left(\varepsilon_{t}^{*}\right)\right]^{-1} \int_{\varepsilon_{t}(i) \geq \varepsilon_{t}^{*}} \varepsilon_{t}(i) d i
\end{aligned}
$$

Define $P\left(\varepsilon_{t}^{*}\right) \equiv\left[\int_{\varepsilon \geq \varepsilon_{t}^{*}} \varepsilon d F(\varepsilon)\right]\left[1-F\left(\varepsilon_{t}^{*}\right)\right]^{-1}$ as the measure of aggregate investment efficiency, we obtain equation (36). Equation (30) implies $(1-\alpha)\left[\frac{Y_{t}}{N_{t}}\right]^{1-\sigma} A_{t}^{\sigma}=w_{t}$. Since the capitallabor ratio is identical across firms, it must be true that $\frac{k(i)}{n(i)}=\frac{K}{N}$. It follows that the aggregate 
production function is given by $Y_{t}=\left\{\alpha K_{t}^{\sigma}+(1-\alpha)\left[A_{t} N_{t}\right]^{\sigma}\right\}^{\frac{1}{\sigma}}$. By the property of constant returns to scale, the defined function $R\left(w_{t}, A_{t}\right)$ in equation (17) is then the capital share, $R_{t}=\alpha\left(\frac{Y_{t}}{K_{t}}\right)^{1-\sigma}$, which equals the marginal product of aggregate capital. Because $\int_{0}^{1} b_{t}(i) d i=0$ and $s_{t+1}(i)=1$, the aggregate dividend is given by $D_{t}=Y_{t}-I_{t}-w_{t} N_{t}$. Hence, the household resource constraint becomes $C_{t}+I_{t}=Y_{t}$.

\section{Appendix III.A. Proof of Proposition 3}

Proof. Given $\varepsilon^{*}$, equation (32) determines the real interest rate $r=\frac{1}{\beta Q\left(\varepsilon^{*}\right)}$. Equations (35) and (36) imply the following two relationships in the steady state:

$$
\begin{gathered}
I=\left(R+\frac{\theta}{r}\right) K\left[1-F\left(\varepsilon^{*}\right)\right] \\
\delta K=P\left(\varepsilon^{*}\right) I .
\end{gathered}
$$

Substituting out $r$ and $\frac{I}{K}$ in $(69)$ gives $\frac{\delta}{P\left(\varepsilon^{*}\right)}=\left(R+\beta \theta Q\left(\varepsilon^{*}\right)\right)\left[1-F\left(\varepsilon^{*}\right)\right]$. Hence, the marginal product of capital (or the capital-output ratio) is determined by

$$
R=\frac{\delta}{P\left(\varepsilon^{*}\right)\left[1-F\left(\varepsilon^{*}\right)\right]}-\beta \theta Q\left(\varepsilon^{*}\right)
$$

Since $P(1-F)=\int_{\varepsilon \geq \varepsilon^{*}} \varepsilon d F(\varepsilon)$, equation (31) implies

$$
\frac{1}{\varepsilon^{*} Q\left(\varepsilon^{*}\right)}[1-\beta(1-\delta)]=\frac{\beta \delta}{\left[\int_{\varepsilon \geq \varepsilon^{*}} \varepsilon d F(\varepsilon)\right]}-\beta^{2} \theta
$$

which is equation (40).

Equation (72) has a unique solution for $\varepsilon^{*}$. Notice that the definition of $Q\left(\varepsilon^{*}\right)$ in Proposition 2 implies

$$
\varepsilon^{*} Q\left(\varepsilon_{t}^{*}\right) \equiv \int \max \left(\varepsilon, \varepsilon^{*}\right) d F(\varepsilon)
$$

which is increasing in $\varepsilon^{*}$. The left-hand side of equation (72) is thus monotonically decreasing in $\varepsilon^{*}$, and it is easy to see that the right-hand side is monotonically increasing in $\varepsilon^{*}$. So if there is a solution for $\varepsilon^{*}$, the solution must be unique. 
To prove that a solution exists, define

$$
\Delta\left(\varepsilon^{*}\right) \equiv \frac{1}{\varepsilon^{*} Q\left(\varepsilon^{*}\right)}[1-\beta(1-\delta)]-\frac{\beta \delta}{\left[\int_{\varepsilon \geq \varepsilon^{*}} \varepsilon d F(\varepsilon)\right]}+\beta^{2} \theta
$$

and $\bar{\varepsilon} \equiv \int \varepsilon d F(\varepsilon)$. Clearly, if the product of the minimum and maximum of this metric $\Delta$ is negative, $\Delta\left(\varepsilon_{\min }^{*}\right) \times \Delta\left(\varepsilon_{\max }^{*}\right)<0$, then an interior solution exists. Notice that

$$
\lim _{\varepsilon^{*} \rightarrow \varepsilon_{\min }} \Delta\left(\varepsilon_{\min }\right)=\frac{1}{\bar{\varepsilon}}[1-\beta+\beta \delta]-\frac{\beta \delta}{\bar{\varepsilon}}+\beta^{2} \theta>0
$$

while

$$
\lim _{\varepsilon^{*} \rightarrow \varepsilon_{\max }} \Delta\left(\varepsilon_{\max }\right)=\frac{1}{\varepsilon_{\max }}[1-\beta+\beta \delta]-\infty+\beta^{2} \theta<0
$$

So there must be an interior solution $\varepsilon^{*}$ such that $\Delta\left(\varepsilon^{*}\right)=0$. This establishes the existence and uniqueness of the cutoff $\varepsilon^{*}$. Given $\varepsilon^{*}$, the marginal product of aggregate capital $R$ is given by (71). To obtain (41), use (72) to substitute out $\beta \theta Q\left(\varepsilon^{*}\right)$ in equation (71) and obtain

$$
\begin{aligned}
R & =\frac{\delta}{\int_{\varepsilon \geq \varepsilon^{*}} \varepsilon d F(\varepsilon)}-\frac{\delta Q\left(\varepsilon^{*}\right)}{\left[\int_{\varepsilon \geq \varepsilon^{*}} \varepsilon d F(\varepsilon)\right]}+\frac{1}{\varepsilon^{*}}\left[\frac{1}{\beta}-(1-\delta)\right] \\
& =\frac{1}{\varepsilon^{*}}\left[\frac{1}{\beta}-1+\delta\right]-\delta \frac{\frac{1}{\varepsilon^{*}} \int_{\varepsilon \geq \varepsilon^{*}} \varepsilon d F(\varepsilon)-\left[1-F\left(\varepsilon^{*}\right)\right]}{\int_{\varepsilon \geq \varepsilon^{*}} \varepsilon d F(\varepsilon)}
\end{aligned}
$$

Rearranging terms yields equation (41). So equation (39) can be used to determine the output capital ratio as in (41).

Equation (69), together with equation (41), implies

$$
\frac{I}{Y}=\frac{I}{K} \frac{K}{Y}=\left[R+\frac{\theta}{r}\right]\left[1-F\left(\varepsilon^{*}\right)\right]\left(\frac{\alpha}{R}\right)^{\frac{1}{1-\sigma}},
$$

which is equation (42). Using the resource constraint, we obtain $\frac{I}{Y}=1-\frac{C}{Y}$. Equations (37) and (38) can be used to solve the steady-state labor supply $(N)$ :

$$
\frac{1}{C}(1-\alpha)\left(\frac{Y}{N}\right)^{1-\sigma}=N^{\gamma}
$$


which is identical to

$$
\frac{Y}{C}(1-\alpha)\left(\frac{N}{Y}\right)^{\sigma}=N^{\gamma+1}
$$

Invoking the aggregate production function (34) we have

$$
(1-\alpha)\left(\frac{N}{Y}\right)^{\sigma}=1-\alpha\left(\frac{K}{Y}\right)^{\sigma}=1-\alpha\left(\frac{R}{\alpha}\right)^{\frac{\sigma}{\sigma-1}}
$$

Substituting this into equation (80) yields equation (43). Again, using (34) we have

$$
Y^{\sigma}=\alpha K^{\sigma}+(1-\alpha) N^{\sigma}
$$

Using equation (81) to substitute out $K^{\sigma}$ and rearranging terms yield equation (44). Obtaining the real wage at steady state is straightforward. Since an interior solution of the cutoff exists and is unique, equations (78) to (82) establish the existence and uniqueness of the steady-state values of the other variables in the economy.

\section{Appendix III.B. Proof of Corollary 2}

Proof. Consider first $\frac{\partial \varepsilon^{*}}{\partial \theta}$. Notice that $\varepsilon^{*}$ is defined implicitly by the function

$$
\Gamma\left(\varepsilon^{*}, \theta\right) \equiv \frac{1}{\varepsilon^{*} Q\left(\varepsilon^{*}\right)}[1-\beta(1-\delta)]-\frac{\beta \delta}{\left[\int_{\varepsilon \geq \varepsilon^{*}} \varepsilon d F(\varepsilon)\right]}+\beta^{2} \theta=0 .
$$

So

$$
\frac{\partial \varepsilon^{*}}{\partial \theta}=-\frac{\partial \Gamma\left(\varepsilon^{*}, \theta\right) / \partial \theta}{\partial \Gamma\left(\varepsilon^{*}, \theta\right) / \partial \varepsilon} .
$$

It is easy to see that $\partial \Gamma\left(\varepsilon^{*}, \theta\right) / \partial \varepsilon<0$ and $\partial \Gamma\left(\varepsilon^{*}, \theta\right) / \partial \theta>0$, so clearly $\frac{\partial \varepsilon^{*}}{\partial \theta}>0$. By the definition of $P\left(\varepsilon^{*}\right)$,

$$
\frac{\partial P}{\partial \varepsilon^{*}}=\frac{-\left[1-F\left(\varepsilon^{*}\right)\right] \varepsilon^{*} f\left(\varepsilon^{*}\right)+f\left(\varepsilon^{*}\right)\left[\int_{\varepsilon \geq \varepsilon^{*}} \varepsilon d F(\varepsilon)\right]}{\left[1-F\left(\varepsilon^{*}\right)\right]^{2}}>0 .
$$

So $\frac{\partial P}{\partial \theta}=\frac{\partial P}{\partial \varepsilon^{*}} \frac{\partial \varepsilon^{*}}{\partial \theta}>0$. But by definition, $Q \equiv \int \max \left(\frac{\varepsilon}{\varepsilon_{t}^{*}}, 1\right) d F(\varepsilon)$, so it is easy to see that $\frac{\partial Q}{\partial \varepsilon^{*}}<0$ and $\frac{\partial Q}{\partial \varepsilon^{*}}=\frac{\partial Q}{\partial \varepsilon^{*}} \frac{\partial \varepsilon^{*}}{\partial \theta}<0$. In the steady state, $r=\frac{1}{\beta Q}$, so $\frac{\partial r}{\partial \theta}>0$. Finally, since 
$R=\frac{1}{\varepsilon^{*}}\left[\frac{1}{\beta}-1\right]+\frac{\delta}{P\left(\varepsilon^{*}\right)}$ and since both $\varepsilon^{*}$ and $P\left(\varepsilon^{*}\right)$ are increasing in $\theta$, so $\frac{\partial R}{\partial \theta}<0$.

It remains to be established that for $-\infty<\sigma<1$,

$$
\frac{\partial w}{\partial \theta}>0, \quad \frac{\partial(Y / N)}{\partial \theta}>0, \quad \frac{\partial(K / N)}{\partial \theta}>0 \text { and } \frac{\partial(Y / K)}{\partial \theta}<0 .
$$

Given that $w=(1-\alpha)\left(\frac{Y}{N}\right)^{1-\sigma}, R=\alpha\left(\frac{Y}{K}\right)^{1-\sigma}$, and $Y^{\sigma}=\alpha K^{\sigma}+(1-\alpha) N^{\sigma}$, we obtain

$$
(1-\alpha)^{\frac{1}{1-\sigma}} w^{\frac{\sigma}{\sigma-1}}+\alpha^{\frac{1}{1-\sigma}} R^{\frac{\sigma}{\sigma-1}}=1
$$

Since $\frac{\partial R}{\partial \theta}<0$, it must be true that $\frac{\partial w}{\partial \theta}>0$. By $w=(1-\alpha)\left(\frac{Y}{N}\right)^{1-\sigma}$, we then have $\frac{\partial(Y / N)}{\partial \theta}>0$. Since $R=\alpha\left(\frac{Y}{K}\right)^{1-\sigma}$ and $\frac{\partial R}{\partial \theta}<0$, we also have $\frac{\partial(Y / K)}{\partial \theta}<0$. Finally, given that $\frac{w}{R}=\frac{1-\alpha}{\alpha}\left[\frac{K}{N}\right]^{1-\sigma}$, $\frac{\partial w}{\partial \theta}>0$, and $\frac{\partial R}{\partial \theta}<0$, it must be true that $\frac{\partial(K / N)}{\partial \theta}>0$.

\section{Appendix IV. Robustness of the L-Shaped Relationship}

Here we show that the L-shaped non-linear relationship between FD and aggregate volatility is robust to the inclusion of additional control variables. For this purpose, we run multivariate non-linear regression by including as additional controls the following independent variables: the real per-capita GDP growth, real interest rate, openness to trade (trade volume-to-GDP ratio), terms of trade, international capital flows, CPI inflation, government spending, money supply (M2) growth, money stock(M2)-to-GDP ratio, etc., into a model with aggregate investment volatility as the dependent variable and total private credit-to-GDP ratio (measure of FD) as the chief independent variable. ${ }^{45}$ The results are presented in Figure IV. The figure shows the predicted investment volatility by the total private credit-to-GDP ratio for (i) the whole sample (Panel A), (ii) the OECD countries (Panel B), (iii) the emerging and newly industrialized (ENI) economies plus the less developed (LD) countries (Panel C), and (iv) the regression residuals from the multivariable non-linear regression when the total credit-to-GDP ratio is excluded

\footnotetext{
${ }^{45}$ The results are broadly similar for the volatility of GDP and the other measures of FD.
} 
from the set of independent variables (Panel D). ${ }^{46}$

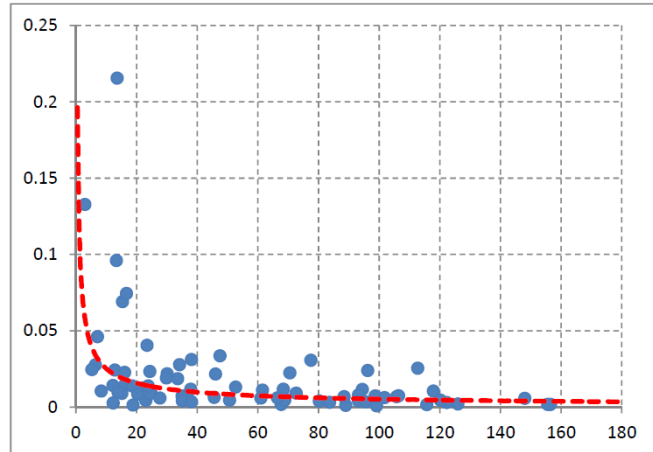

A. Full Sample

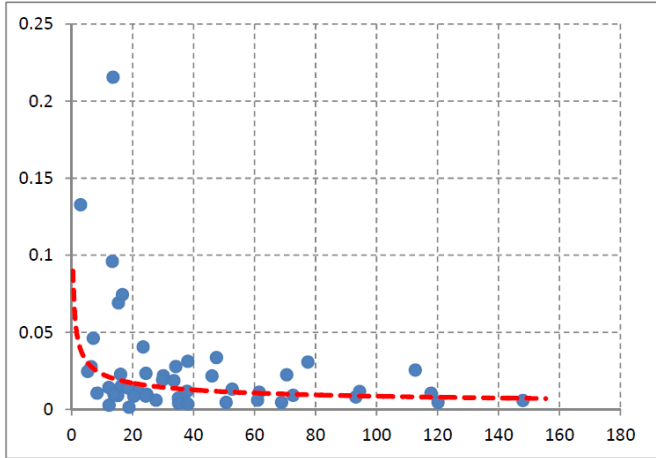

C. ENI and LD Countries

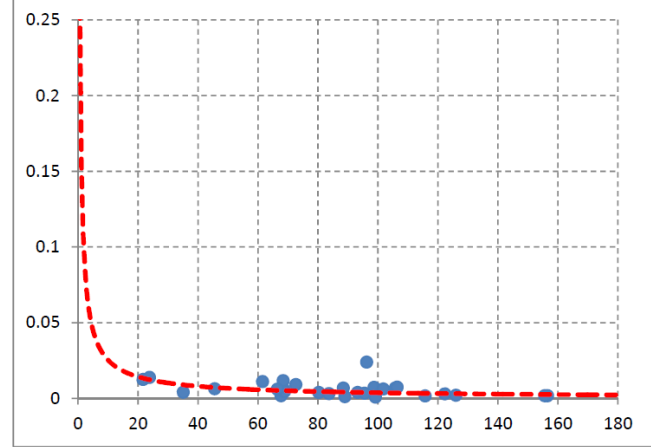

B. OECD Countries

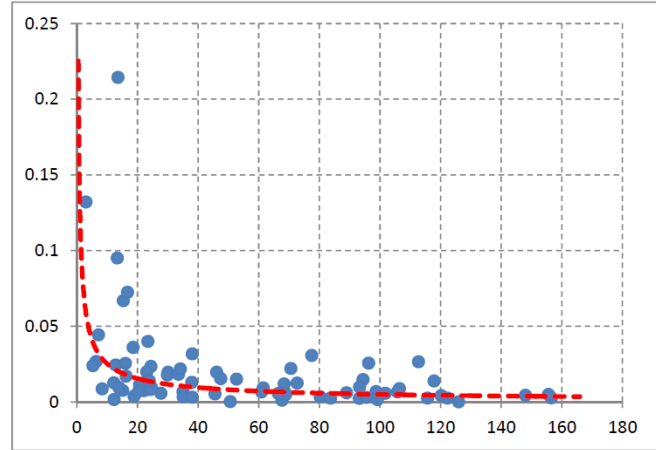

D. Residuals

Figure IV. Predicted Investment Volatility (y-axis) by FD (x-axis).

\section{Appendix V. Data}

See our online Appendix A (also available upon request).

\section{Appendix VI. Other Robustness Analyses}

See our online Appendix B (also available upon request).

\footnotetext{
${ }^{46}$ The cases for the emerging countries and the less developed countries are not reported separately because the sample size of LDCs is too small to run the multivariable non-linear regression. In Panel D, the residuals from the regression reflect the component of the investment volatility that is not explained by the independent variables in the absence of the chief independent variable (the total private credit-to-GDP ratio). So it is an alternative way to capture the relationship between aggregate investment volatility and FD. The results in Panel $A$ and Panel D are very similar although not identical, suggesting that the private credit-to-GDP ratio is the chief explanatory variable responsible for the L-shaped nonlinear relationship.
} 